\title{
有机聚合物苂光传感器的研究进展
}

\author{
曹西预 ${ }^{a}$ 罗时荷*, 杨崇岭 $*, b$ 肖 采 ${ }^{a}$ 李晓燕 ${ }^{a}$ \\ 张钧如 ${ }^{a}$ 汪朝阳*, $a$ \\ ( ${ }^{a}$ 华南师范大学化学学院 教育部环境理论化学重点实验室 广州市生物医药分析化学重点实验室 广州 510006) \\ $\left({ }^{b}\right.$ 广东轻工职业技术学院 广州 510300)
}

\begin{abstract}
摘要 有机苂光聚合物具有独特的荧光信号放大特点和良好的光学性质, 可检测特定的分析物种. 通过对其侧链等合 理修饰, 进一步改善其传感性能. 如今, 有机苂光聚合物的合成方法以金属偶联反应为主, 烯烃加聚和缩合反应相对 较少. 以聚合物的荧光来源为主线, 从反应类型的角度, 系统地综述了近些年来荧光性有机聚合物在传感器领域的研 究进展, 特别是对其设计合成、传感应用及检测机理等进行了介绍. 未来, 新型多功能有机荧光聚合物的设计与合成仍 有待进一步深入研究, 是重点发展方向.
\end{abstract}

关键词 有机聚合物荧光传感器; 设计与合成; 金属偶联反应; 苂光传感应用; 检测机理; 多功能

\section{Research Progress of Organic Polymer Fluorescence Sensor}

\author{
Cao, Xiying ${ }^{a}$ \\ Luo, Shihe*,a \\ Yang, Chongling*,b \\ Xiao, Ying ${ }^{a}$ \\ Li, Xiaoyan ${ }^{a}$ \\ Zhang, Junru $^{a} \quad$ Wang, Zhaoyang ${ }^{*, a}$
}

( ${ }^{a}$ Key Laboratory of Theoretical Chemistry of Environment, Ministry of Education, Guangzhou Key Laboratory of Analytical Chemistry for Biomedicine, School of Chemistry, South China Normal University, Guangzhou 510006)

( ${ }^{b}$ Guangdong Industry Polytechnic, Guangzhou 510300)

\begin{abstract}
Organic fluorescent polymers have unique characteristics of fluorescent signal amplification and good optical properties, and can detect specific analytical species. Their sensing performance can be further improved through reasonable modification of their side chains. Nowadays, the organic fluorescent polymers are mainly prepared by metal coupling reactions, and there are also some syntheses involving in addition polymerization and condensation reactions. Taking the fluorescent source of these polymers as the main line, the research progress of the fluorescent organic polymers in the sensor field in recent years is systematically reviewed from the perspective of the type of reaction, especially their design and synthesis, sensing application, detection mechanism are summarized. In the future, it is still to be further investigated to design and synthesize novel multifunctional organic polymer fluorescence sensors as the key development direction.

Keywords organic polymer fluorescence sensor; design and synthesis; metal coupling reaction; fluorescence sensing application; detection mechanism; multifunctional
\end{abstract}

不同的功能性有机聚合物在电池 ${ }^{[1]}$ 、阻燃 ${ }^{[2]}$ 、药物 缓释 ${ }^{[3]}$ 、癌症治疗 ${ }^{[4]}$ 等方面有着广泛的应用, 而苂光性有 机聚合物在实际应用中更是引人注目 ${ }^{[5-6]}$. 这是因为它 们不仅克服了有机苂光小分子的一些局限，而且还能发 挥自身的优势. 例如, 这类有机聚合物可通过便捷的设 计和简单的修饰优化其性能. 同时，因其结构中具有大
量重复单元，激发能可沿聚合物链段转移，从而产生 “信号放大”的苂光增强效应等 ${ }^{77-8]}$. 因此, 苂光性有机聚 合物对化学传感领域产生了深远的影响 ${ }^{[9-10]}$.

鉴于多孔型有机聚合物荧光传感器前文已有相关 综述 ${ }^{[11]}$, 此处重点讨论不涉及它们的有机聚合物苂光传 感材料的合成与应用. 一般而言, 非多孔型的有机聚合

\footnotetext{
* Corresponding authors. E-mail: wangzy@scnu.edu.cn; 2009103069@gdip.edu.cn; pinky_r@163.com Received May 23, 2020; revised June 30, 2020; published online July 22, 2020.

Project supported by the National Natural Science Foundation of China (No. 20772035), the Science and Technology Project of Guangdong Province (No. 2017A010103016), the Key Laboratory of Functional Molecular Engineering of Guangdong Province (No. 2017kf01), and the Science and Technology Program of Guangzhou City (No. 202002030362).

国家自然科学基金(No. 20772035)、广东省科技计划(No. 2017A010103016)、广东省功能分子工程重点实验室(No. 2017kf01)、广州市科技计划(No. 202002030362)资助项目.
} 
物苂光传感器的构建, 既可直接聚合形成共轭结构的苂 光性有机聚合物, 也可通过后期修饰引入不同苂光团形 成. 因此, 本文将常见的有机聚合物荧光传感器分为两 大类, 并从反应类型的角度对苂光性有机聚合物在传感 器领域的应用进行了综述.

\section{1 基于直接聚合法的有机聚合物荧光传感器}

一般而言，通过金属偶联反应、双烯加聚、缩合反 应等可直接合成苂光性有机聚合物. 当聚合物链段中含 有与客体作用的位点时, 通过主体一客体的相互作用, 即可直接应用为识别不同物种的传感器 ${ }^{[12-13]}$. 此外, 也 可将荧光性有机聚合物设计成荧光纳米材料以改善其 传感性能 ${ }^{[14-15]}$.

\section{1 基于金属偶联反应合成的有机聚合物荧光传感器}

利用两种双官能团化合物在过渡金属催化下发生 的偶联聚合反应，是构成有机聚合物菼光传感分子框架 的重要方法 ${ }^{[16]}$. 其中, Sonogashira 反应是常用于构建有 机聚合物荧光传感器的金属偶联反应之一 ${ }^{[17]}$. Sonogashira 反应是在钯配合物催化下卤代芳烃或卤代烯 烃与末端炔烃的交叉偶联反应，常用于合成潜在药物分 子 $^{[18-19]}$ 和有机苂光聚合物 ${ }^{[20]}$ 等. 例如, Jones 课题组 ${ }^{[21-22]}$ 利用二溴代噻吩衍生物和二炔基苯发生的 Sonogashira 反应，合成了可用于金属离子检测的共轭有机聚合物 (Eq. 1).

类似地, Jones 课题组 ${ }^{[23]}$ 以 1,4-二乙炔基苯 1 为原料, 进行了三分子的 Sonogashira 交叉偶联反应, 其中以含 有多个吡啶基的二溴代噻吩引入配位基团, 以含有磺酸 盐结构的二碘代苯引入亲水基团，设计合成了基于多个 氮原子的水溶性荧光传感器 2 (Eq. 2). 向共轭有机聚合 物 $\mathbf{2}$ 的水溶液中加入 $\mathrm{Cu}^{2+}, \mathbf{2}$ 与 $\mathrm{Cu}^{2+}$ 配位, 使 $\mathbf{2}$ 原来在 $530 \mathrm{~nm}$ 处的强荧光峰减弱, 并且随着 $\mathrm{Cu}^{2+}$ 浓度的增加<smiles>C#Cc1cc(OCCC)c(OCCC)cc1C#C</smiles>

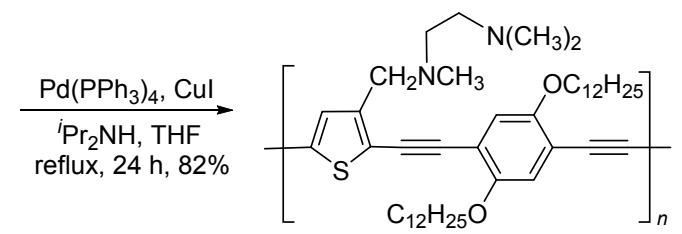

荧光的猝灭率越大. 其他离子对聚合物的苂光强度没有 影响, 故有机聚合物苂光传感器 2 可选择性检测 $\mathrm{Cu}^{2+}$, 检测限为 $1.47 \times 10^{-8} \mathrm{~mol} \cdot \mathrm{L}^{-1}$. 在国内, 也有利用 Sonogashira 反应合成用于金属离子检测的有机聚合物 苂光传感器的报道 ${ }^{[24]}$.

利用 Sonogashira 反应合成的聚合物荧光传感器不 仅可检测单个金属离子，还能对两种金属离子进行检 测 ${ }^{[25]}$. 例如, 朱成建课题组 ${ }^{[26]}$ 合成的噻唑类有机聚合物 (Eq. 3), 由于聚合物传感器与金属离子配位的能力差异, 仅 $\mathrm{Hg}^{2+}$ 和 $\mathrm{Ag}^{+}$能与探针中的 $\mathrm{S}$ 或 $\mathrm{N}$ 配位，导致聚合物的 电子云密度发生变化, 从而影响聚合物的光物理性质, 故可选择性地检测 $\mathrm{Hg}^{2+}$ 和 $\mathrm{Ag}^{+}$. 加入 $\mathrm{Hg}^{2+}$ 或 $\mathrm{Ag}^{+}$后, 有 机聚合物在 $474 \mathrm{~nm}$ 处的苂光发生猝灭, $\mathrm{Hg}^{2+}$ 存在时苂 光颜色由鲜绿色变为无色, 而 $\mathrm{Ag}^{+}$存在时则变成浅绿 色，它们的检测限分别为 $5.1 \times 10^{-7}$ 和 $1.68 \times 10^{-7} \mathrm{~mol}$. $\mathrm{L}^{-1}$.

在溶液中，阴阳离子往往是同时出现，阴阳离子平 衡对生物体具有极其重要的影响, 而对于阴阳离子的同 时检测是一个较大的挑战 ${ }^{[27]}$. 黄飞鹤课题组 ${ }^{[28]}$ 以冠醚 结构修饰的二碘代苯和化合物 1 为原料，利用 Sonogashira 反应生成共轭聚合物 3 (Eq. 4), 其进一步与 “交联剂” 二芳基仲铵盐通过主客体作用形成具有 “交 联网络” 的超分子凝胶，使聚合物 3 的荧光强度不断
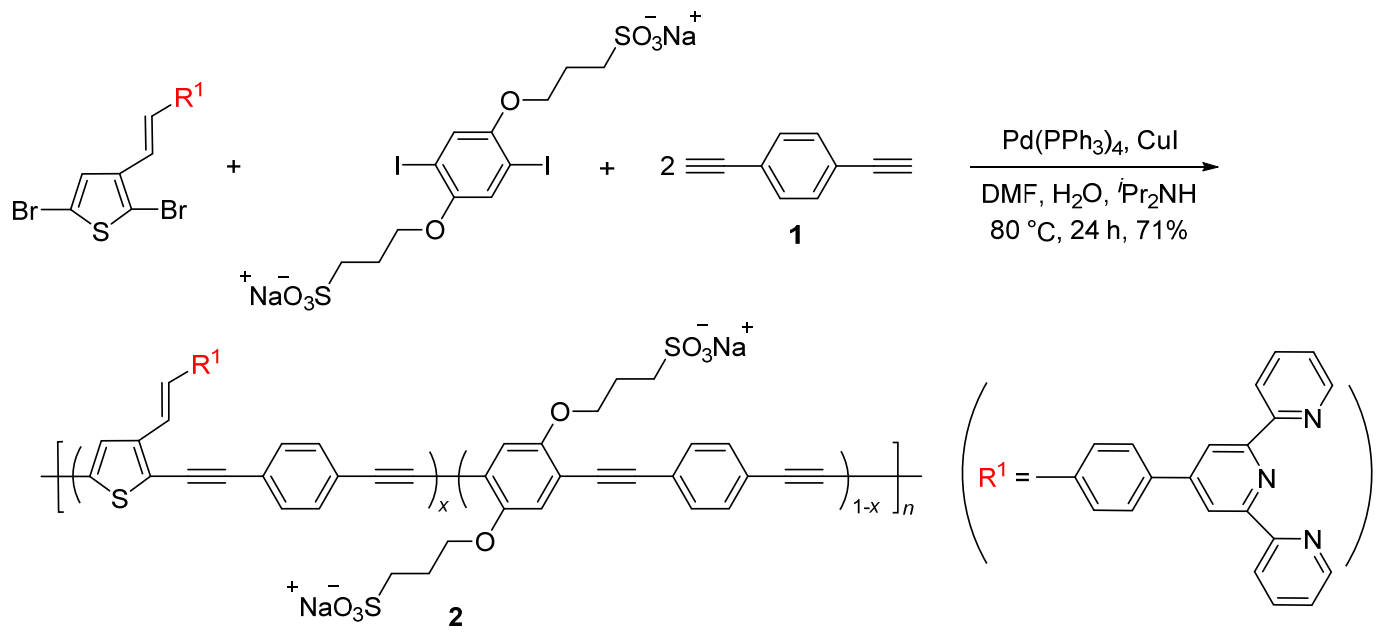
<smiles>Cc1nc2c(Br)ccc(Br)c2s1</smiles><smiles>C#Cc1cc(OCC)c(OCC)cc1C#C</smiles>

$\mathrm{Pd}\left(\mathrm{PPh}_{3}\right)_{4}, \mathrm{Cul}$

$\mathrm{Et}_{3} \mathrm{~N}, \mathrm{DMF}$

$70{ }^{\circ} \mathrm{C}, 48 \mathrm{~h}, 70 \%$<smiles>CCOc1cc(C(F)(F)F)c(OCC)cc1C#Cc1ccc(C#CC(C)(C)C)c2nc(C)sc12</smiles>

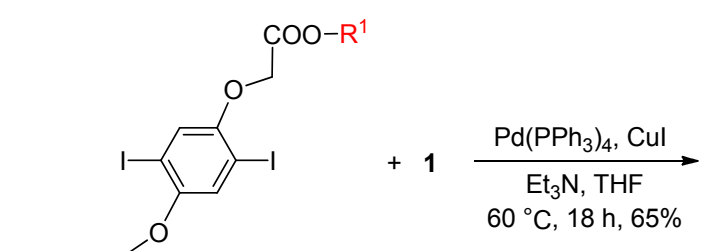

(4)

降低, 发射峰由 $440 \mathrm{~nm}$ 红移到 $447 \mathrm{~nm}$, 颜色由亮蓝色 变为淡蓝色. 分别加入 $\mathrm{K}^{+} 、 \mathrm{Cl}^{-}$、碱, 或者加热, 均可破 坏超分子网络结构, 导致荧光强度变化. 因此, 该凝胶 具有较好的多种荧光响应功能.

利用有机聚合物菼光传感器检测有机物方面的报 道也很多. 例如, Adachi 课题组 ${ }^{[29]}$ 利用 Sonogashira 反 应，合成了 “turn-on” 型有机聚合物荧光传感器(Eq. 5), 其可用于检测甲基紫精. 但基于 Sonogashira 反应合成 有机聚合物荧光传感器的应用中, 更为常见的是用于检 测硝基芳香族爆炸物(NAE $)^{[30]}$, 特别是苦味酸(PA) ${ }^{[31-32]}$.

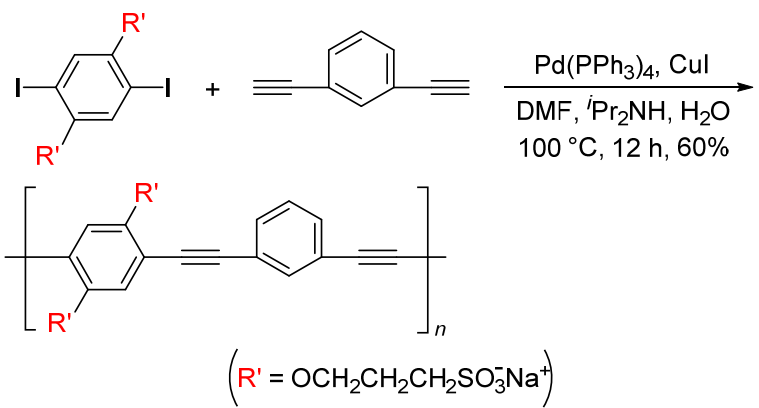

PA 是典型的 NAE, 具有较高的爆破能量、毒性和 水溶性, 对眼睛、皮肤、呼吸道和消化道有毒害作用, 长
期接触还会对肝脏和肾脏造成损害 ${ }^{[33-35]}$. 在爆破作业、 军事活动、炸药储存等过程中, PA 容易在周围土壤和地 下水中残留, 给环境和人体健康带来严重危害 ${ }^{[36]}$. 因 此, 改善探针的水溶性, 对 PA 进行苂光检测的研究近 来受到重视 ${ }^{[37]}$. 这种策略也被应用于有机聚合物苂光 传感器检测 PA, 如冯国栋课题组 ${ }^{[38]}$ 将具有良好水溶性 的精氨酸引入到有机苂光聚合物中得到 PA 探针 (Scheme 1).
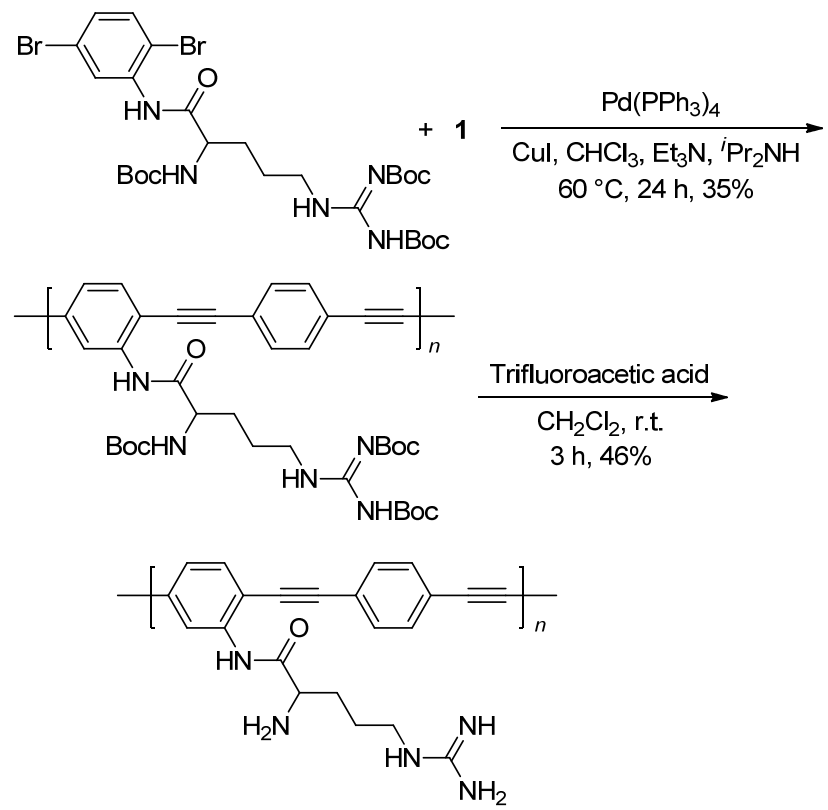

图式 1 PA 检测用聚合物探针的合成

Scheme 1 Synthesis of polymeric probe for PA

有机苂光聚合物探针不仅可以对 PA 等 NAE 类有机 化合物进行检测，还能特异性检测血红素蛋白等生物活 性物质 ${ }^{[39]}$ ，因此具有一定水溶性的有机苂光聚合物探 针近来很受重视 ${ }^{[40]}$. 引入多个带有电荷的侧链, 是改善 蛋白质类苂光探针水溶性的主要方法 ${ }^{[41-42]}$ ，也可利用冠 醚修饰有机苂光聚合物 ${ }^{[43]}$ (图 1).

除了 Sonogashira 反应之外，利用其它的钯催化金 属偶联反应来构建有机聚合物苂光传感器也有报道 ${ }^{[44]}$, 特别是利用卤代烃与有机硼化合物之间发生的 Suzuki 反应 ${ }^{[45-46]}$ ，所得聚合物探针用于金属检测的居多 ${ }^{[47]}$. 其 中，利用兼有配位作用的含氮芳杂环结构 ${ }^{[48]}$ (特别是易

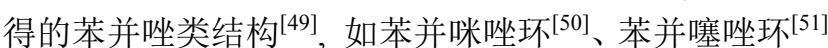
等芳杂环)来巧妙地设计功能化的有机聚合物苂光探 针 $^{[52]}$, 是近来的一个研究热点.

例如, 冯丽恒课题组 ${ }^{[53]}$ 利用 Suzuki 反应合成了一 种以喹啉和芴基为主链、苯并噻唑基为侧链的聚合物荧 光探针(Eq. 6). 该探针中喹啉和芴基是电子给体，苯并 噻唑是电子受体. 在 $\mathrm{Zn}^{2+}$ 存在的情况下, 由于 $\mathrm{Zn}^{2+}$ 与 $\mathrm{N} 、 \mathrm{O}$ 原子的络合作用, 芴和喹啉分子内的电子可转移 
到苯并噻唑基上, 使探针的乙醇溶液在 $555 \mathrm{~nm}$ 处出现 了一个新的苂光发射峰. 随着 $\mathrm{Zn}^{2+}$ 浓度的增加, 苂光强 度不断增强, 苂光颜色由蓝色变为黄色. 因此, 该比率 型探针可对 $\mathrm{Zn}^{2+}$ 进行可视化的检测, 检测限为 $5.0 \times$ $10^{-8} \mathrm{~mol} \cdot \mathrm{L}^{-1}$.
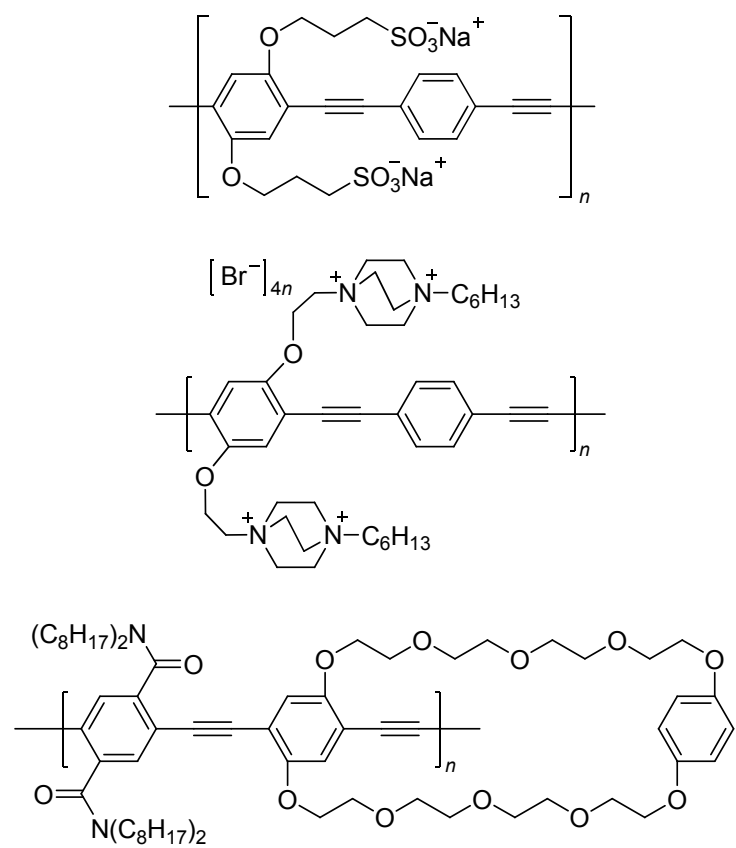

图 1 部分生物活性物质检测用聚合物探针的分子结构

Figure 1 Molecular structures of some probes for bioactive substance

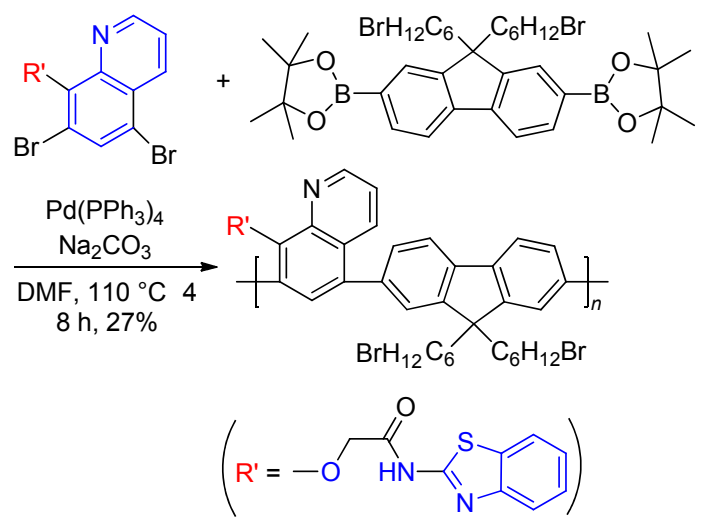

苯并氮杂环有机聚合物探针也可以用来检测一些 有机物 ${ }^{[54]}$. 例如, 何庆国课题组 ${ }^{[55]}$ 利用氟原子个数不同 的苯并噻二唑溴化物与芴类化合物发生 Suzuki 偶联反 应, 获得了一系列以苯并噻二唑为受体的固态聚合物 (6 9, 图 2). 由于聚合物中 $\mathrm{F}$ 原子与有机胺的胺基形成 氢键和静电作用, $N$-甲基苯乙胺蒸汽会导致聚合物膜苂 光强度降低, 适当地引入 $\mathrm{F}$ 原子, 使探针与有机胺之间 的相互作用力增强, 更易发生光致电子转移(PET)过程, 从而影响聚合物的选择性和灵敏度. 但是, 过强的相互 作用会导致聚合物较差的传感性能, 比如探针 8. 相比
之下，探针 7 的灵敏度更高，但其选择性低于探针 6 . 因 此，若是将探针 6 和 7 中的结构单元同时引入了分子中, 可形成具有中等强度相互作用的复合共轭聚合物 9, 其 不仅对 $N$-甲基苯乙胺蒸汽的检出限低达 $4.0 \times 10^{-8}$ $\mathrm{mol} \cdot \mathrm{L}^{-1}$, 而且具有较高的选择性和良好的稳定性.
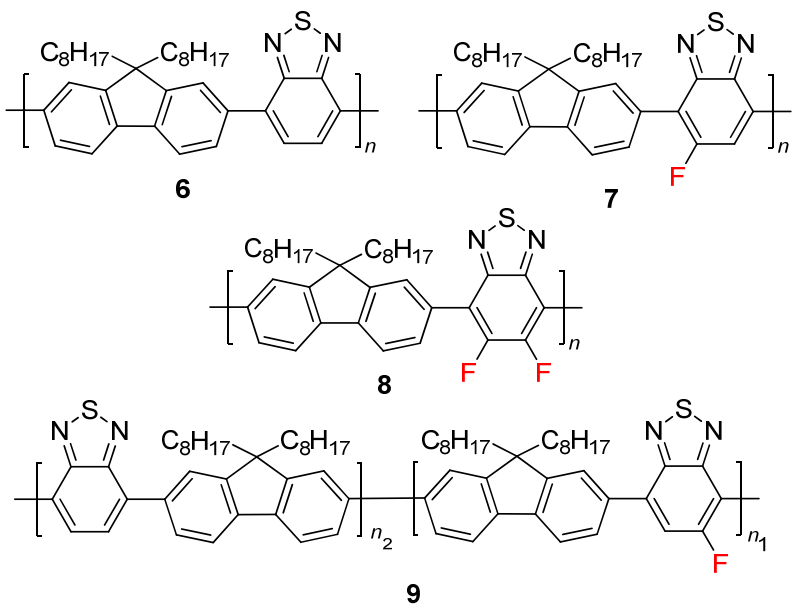

图 2 探针 6、7、8 和 9 的分子结构

Figure 2 Molecular structures of probes 6, 7, 8 and 9

近年来, 生物体内外微量氟离子的识别与检测受到 了越来越多的关注 ${ }^{[56]}$. 其中, 基于氢键作用, 设计氟离 子荧光探针受到重视 ${ }^{[57]}$. 例如, 薛善锋课题组 ${ }^{[58]}$ 利用 Suzuki 反应构建了含多个内酰胺基团的不溶性 $\mathrm{F}^{-}$检测 传感膜 P-2H (Scheme 2). 原来的 P-2H 固体膜为粉红色, 当 $\mathrm{F}^{-}$存在时, 氢键的形成导致 $\mathrm{P}-2 \mathrm{H}$ 膜的吸收峰由 515 , $555 \mathrm{~nm}$ 分别红移到 $565,615 \mathrm{~nm}$, 且吸收峰强度降低, 膜 的颜色由粉红色变为蓝色. 在酸性条件下 $($ 盐酸或乙酸 溶液), 所键合的 $\mathrm{F}^{-}$被洗脱掉, $\mathrm{P}-2 \mathrm{H}$ 膜的颜色恢复原来 的粉红色, 且再生了原来的传感能力. 因此, P-2H 膜不 仅可以作为 $\mathrm{F}^{-}$的传感器, 也可以作为 $\mathrm{F}^{-}$的提取剂.

单重态氧是氧分子的高反应性激发态，是造成生物 分子和有机光电材料的光化学氧化损伤的重要原因之 一, 故对单线态氧的检测十分重要. Nesterov 课题组 ${ }^{[59]}$ 以 $1,4-$ 二溴并四苯和双乙烯基嗍酸酯为原料, 利用 Suzuki 偶联反应合成了共轭聚合物(Eq. 7). 其中, 并四 苯基团可作为单线态氧的反应位点，反应之后产生一个 内过氧化物，使聚合物荧光强度显著增强. 同时，并四 苯环的 1,4 位与 ${ }^{1} \mathrm{O}_{2}$ 反应后, 聚合物主链中 $\pi$ 电子共轭被 破坏, 导致聚合物在 $500 \mathrm{~nm}$ 左右的紫外吸收峰强度降 低, 而 $385 \mathrm{~nm}$ 左右的吸收峰无明显变化.

此外，利用 Suzuki 偶联反应所合成的有机苂光聚合 物, 也可被设计成为各种生物传感器(图 3). 例如, 唐艳 丽课题组 ${ }^{[60]}$ 利用 Suzuki 反应, 设计合成了含低聚氧乙 烯侧链的官能团化水溶性胰凝乳蛋白酶聚合物荧 
<smiles>O=C(OC(=O)C1N(C(=O)c2ccccc2)C(=O)C2C(c3ccc(Br)cc3)=C(c3ccc(Br)cc3)C(=O)N21)c1ccccc1</smiles>

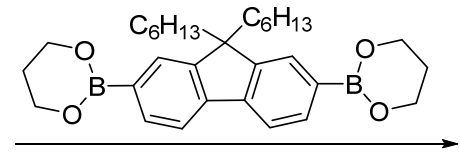

$\mathrm{Pd}\left(\mathrm{PPh}_{3}\right)_{4}, \mathrm{~K}_{2} \mathrm{CO}_{3}$, toluene $100{ }^{\circ} \mathrm{C}, 8 \mathrm{~h}, 54 \%$

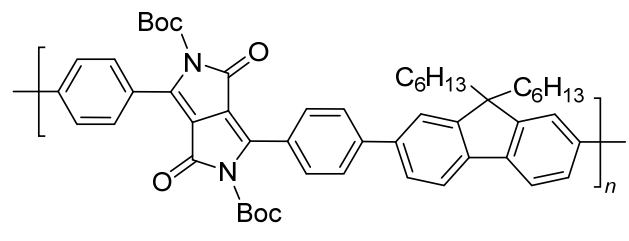

Boc

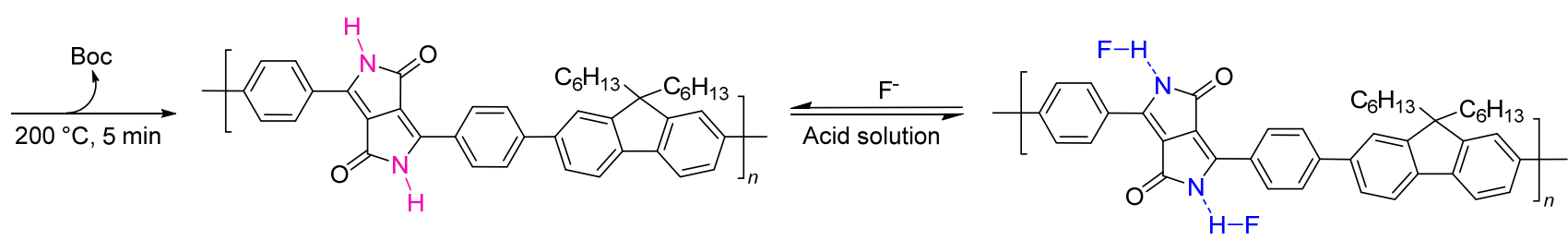

图式 $2 \mathrm{~F}^{-}$探针的合成及作用机理

Scheme 2 Synthesis of probe $\mathrm{F}^{-}$and its interaction mechanism
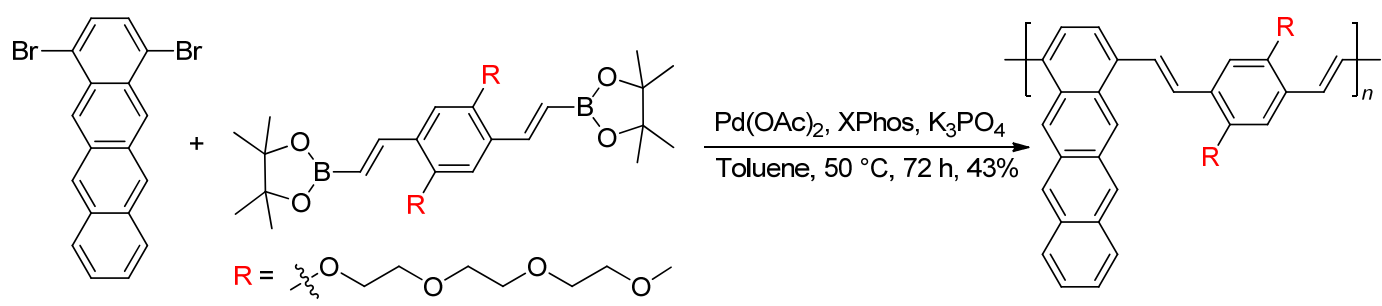

光探针 10; Lee 课题组 ${ }^{[61]}$ 利用聚合物与多肽组成的体系, 建立了对胰蛋白酶可定性和定量检测的有机聚合物荧 光探针 11; 成义祥课题组 ${ }^{[62]}$ 利用 $\mathrm{Cu}^{2+}$ 配位的聚合物, 设 计了一种高选择性的组氨酸苂光传感器 12 ; 成永强课 题组 ${ }^{[63]}$ 基于 Suzuki 反应, 设计了离子型高灵敏度的 miRNA 比率型苂光探针 $\mathbf{1 3}$.

不仅如此, 有机苂光聚合物探针在生物成像中也发 挥着广泛的应用, 尤其是体内成像的发展已显示出广泛 的分子诊断和治疗应用潜力. 例如, 最近吴长峰课题 组 ${ }^{[64]}$ 以苯并噻吩衍生物作为受体, 与具有聚集诱导发 光(AIE)特性的吩噻嗪衍生物在钯催化下通过 Suziki 反 应(Eq. 8), 合成了具有 AIE 和抗聚集导致猝灭(Anti$\mathrm{ACQ}$ )双重荧光增强效应的近红外发光聚合物量子点. 聚合物中葱作为大的侧链基团, 产生的空间位阻会削弱 聚集状态下主链的链间和链内相互作用, 从而显示 Anti-ACQ 效应. 这两种荧光效果使聚合物在近红外二 区内(NIR-II: $1000 \sim 1700 \mathrm{~nm}$ )具有较强的苂光响应，可 对小鼠脑部乃至全身进行苂光成像.

当然，除 Suziki 金属偶联反应之外，利用有机锡试 剂和有机卤化物在钯催化下发生的 Stille 反应(Eq. 9), 也可构建在近红外二区具有强发光性能的有机聚合物 苂光探针, 其可用于脑血管成像和肿瘤诊断 ${ }^{[65]}$.

\section{2 基于聚合反应的聚合物传感器}

利用传统的聚合反应, 特别是烯烃之间的加聚反 应, 也能直接制备有机聚合物苂光传感器 ${ }^{[66]}$, 并且有多 种应用 ${ }^{[67]}$, 特别是检测水溶液中的金属离子 ${ }^{[68]}$. 例如,
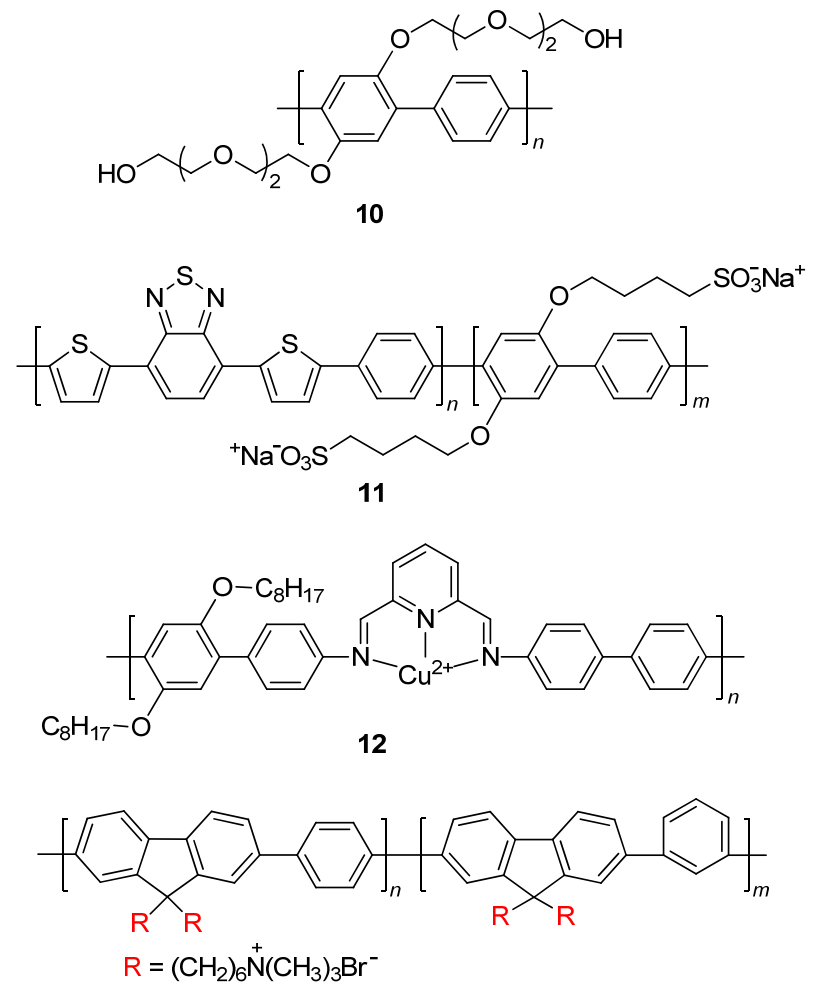

13

图 3 探针 10、11、12 和 13 的分子结构

Figure 3 Molecular structures of probes 10, 11, 12 and 13

Garcia 课题组 ${ }^{[69]}$ 报道, 将亲水性吡咯烷酮单体 14 和丙 烯酸羟乙酯 15 (图 4)与可提供金属离子结合位点的水杨 醛苯甲酰肼单体 16 共聚, 可得到用于纯水溶液中 $\mathrm{Al}^{3+}$ 


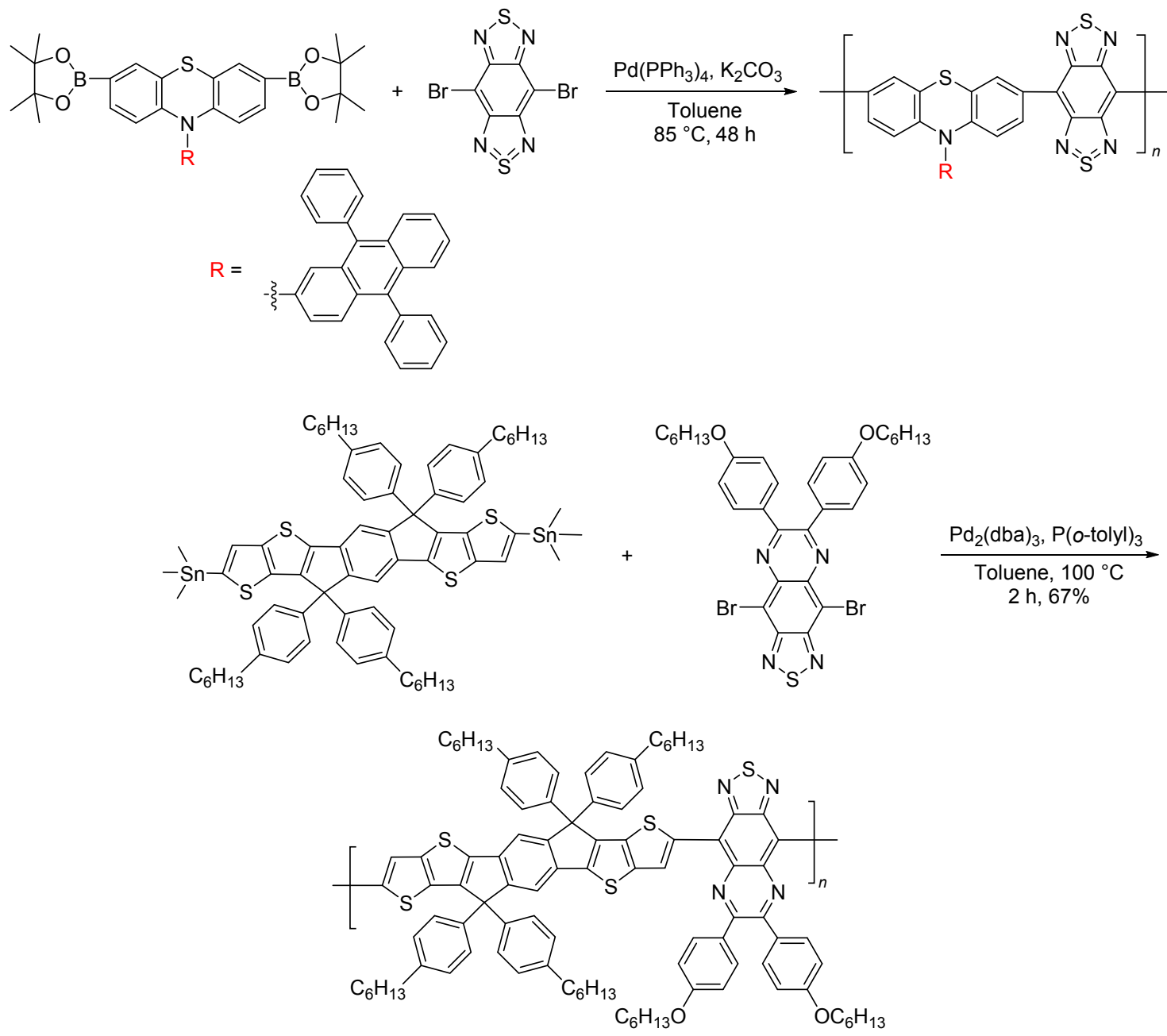

检测的有机聚合物荧光传感器. 利用与 $\mathrm{Al}^{3+}$ 螯合后导致 的苂光增强响应, 该传感器可快速、灵敏地对环境中的 $\mathrm{Al}^{3+}$ 进行检测.

多功能荧光探针的设计、合成与应用日益受到重 视 ${ }^{[70]}$, 多金属离子探针的开发不断被报道 ${ }^{[71]}$, 基于不同 功能烯烃单体制备此目标的有机聚合物荧光传感器也 是可能的 ${ }^{[72]}$. 例如, 耿同谋课题组 ${ }^{[73]}$ 以具有强荧光性生 色团的罗丹明 B 衍生物 17(图 4)为原料, 与亲水性单体 14 共聚, 制备了水溶性有机聚合物荧光传感器. 聚合物 结构单体 17 中的 $\mathrm{O} 、 \mathrm{~N}$ 原子作为结合位点能与 $\mathrm{Cr}^{3+}$ 、 $\mathrm{Fe}^{3+}$ 和 $\mathrm{Hg}^{2+}$ 结合, 诱导罗丹明基团开环, 使聚合物苂光 出现不同程度的增强. 在紫外灯下, 可观察到滴加了 $\mathrm{Cr}^{3+}$ 或 $\mathrm{Hg}^{2+}$ 的溶液有强度增强的橙红色荧光, 同时溶液 颜色由无色变为粉红色. 当加入 $\mathrm{Fe}^{3+}$ 时, 溶液苂光变化 较小, 但聚合物溶液颜色由无色变为棕黄色. 因此, 该 荧光传感器可检测 $\mathrm{Cr}^{3+} 、 \mathrm{Hg}^{2+}$ 和 $\mathrm{Fe}^{3+}$, 它们的检测限分 别为 $2.20 \times 10^{-12} 、 2.39 \times 10^{-12}$ 和 $1.11 \times 10^{-12} \mathrm{~mol} \cdot \mathrm{L}^{-1}$.

乙烯吡咯烷酮单体不仅可以用于共聚制备有机聚 合物苂光传感器, 而且均聚得到的聚乙烯吡咯烷酮也可

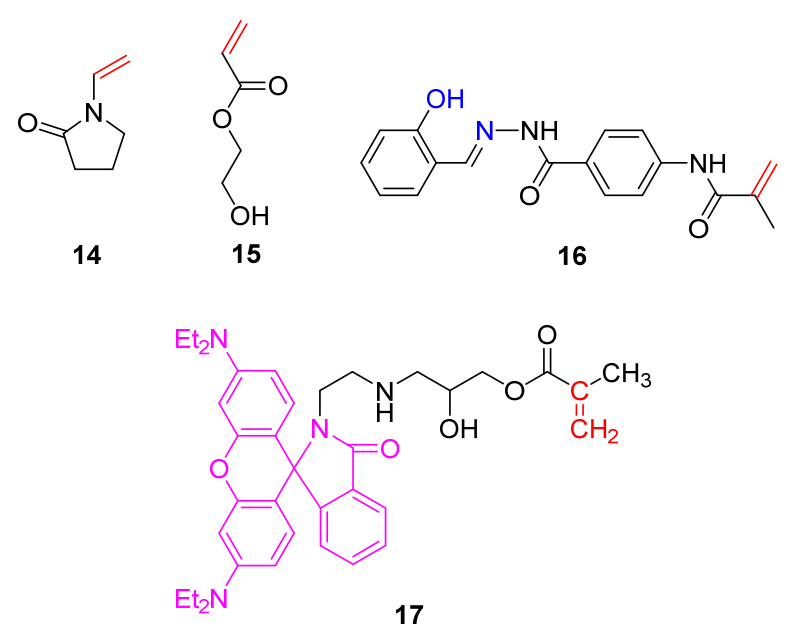

图 4 单体 14、15、16 和 17 的分子结构

Figure 4 Molecular structures of monomers 14, 15, 16 and 17

用于有机聚合物苂光传感器. 例如, Terra 课题组 ${ }^{[74]}$ 先合 成聚乙烯吡咯烷酮, 在溶剂中其与 $\mathrm{Eu}^{3+}$ 掺杂, 再利用静 电纺丝技术制成传感器 18 (图 5). 当传感器 18 置于挥发 性气态 $\mathrm{NH}_{3}$ 中时, 由于 $\mathrm{NH}_{3}$ 分子体积小、电子密度高, 可以很好地与传感器 18 发生相互作用, 使其几何结构 
发生形变, 导致苂光发生猝灭; 该猝灭过程为动态猝灭 和静态猝灭共同作用的结果. 其他挥发性有机物, 如三 乙胺、丙酮、乙酸、甲苯、四氢呋喃和氯仿等, 对 $\mathrm{NH}_{3}$ 的检测没有影响.

葡萄糖是维持细胞稳态和细胞增殖的主要碳供体 和能源, 故监测葡萄糖摄取或葡萄糖浓度的变化很重 要. 在一种以葱及苯硼酸酯基为发光团的葡萄糖传感器 19(图 5)中, 有机铵盐结构使其具有细胞穿透性. 由于聚 合物与葡萄糖分子之间的光致电子转移效应, 使得聚合 物在 $445 \mathrm{~nm}$ 处的苂光强度随着葡萄糖浓度的增加而增 强, 且在浓度为 $0.1 \sim 1.0 \mathrm{mmol} \cdot \mathrm{L}^{-1}$ 范围内具有很好的 线性关系, 检测限为 $4.7 \times 10^{-3} \mathrm{~mol} \cdot \mathrm{L}^{-1}$. 因此, 传感器 19 可用于检测细胞内葡萄糖的含量 ${ }^{[75]}$.

利用特殊的四臂型引发剂, 功能化的烯烃衍生物还 可通过自由基加成聚合反应构建星型的有机聚合物苂 光探针, 如 Hudson 课题组 ${ }^{[76]}$ 所得到的系列具有温度响
应型的荧光聚合物(Eq. 10). 他们的实验表明，这些有机 聚合物菼光传感器在生物成像、药物输送和温度感测方 面具有实用性.

除了加聚反应外，缩聚反应作为另一大传统的聚合 反应，也可以用来合成有机聚合物荧光传感器 ${ }^{[77]}$. 其 中, 由二胺与二酸酐单体缩聚得到的含有芳基结构聚酰 亚胺(PI)类比较常见 ${ }^{[78]}$. 若是芳基上存在羟基，其能与 $\mathrm{F}^{-}$发生强相互作用，形成氢键，以高选择性和高灵敏度 可视化的检测 $\mathrm{F}^{-[79]}$. 甚至可以利用氟离子易于与水结 合的原理(Scheme 3), 基于其对 $\mathrm{F}^{-}$高选择性检测, 利用 聚合物与 $\mathrm{F}^{-}$所形成的体系，对有机溶剂 [二甲基亚砜 (DMSO)、 $N, N$-二甲基甲酰胺(DMF)]中痕量水进行检测. 将微量水添加到聚合物氟化物络合物的无水 $\mathrm{DMSO} / \mathrm{DMF}$ 溶液中, 该体系的紫外吸收光谱逐渐恢复 到纯有机聚合物溶液的原始状态，且肉眼可见溶液的颜 色由浅黄绿色变为原来的无色. 因此, 这种可设计成便

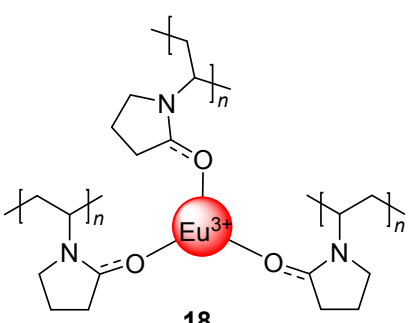

18

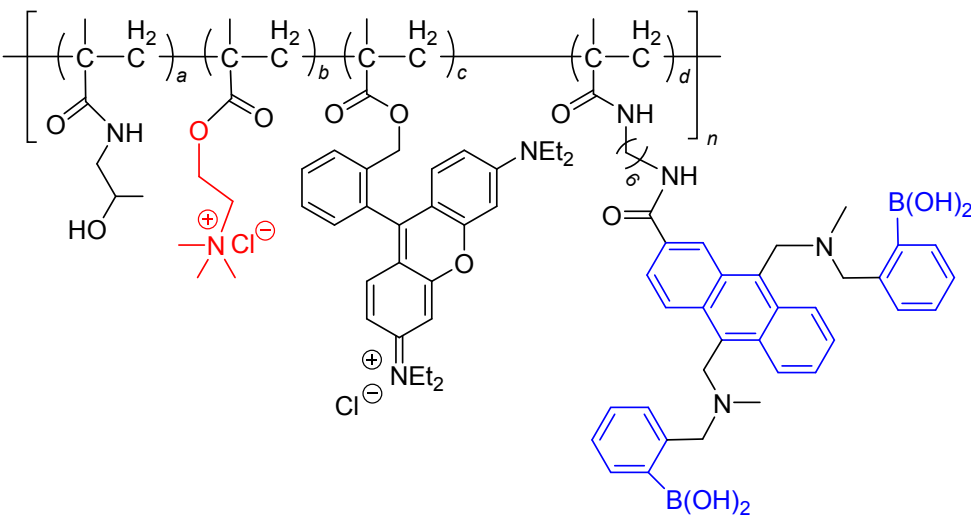

19

图 5 探针 18 和 19 的分子结构

Figure 5 Molecular structures of probes 18 and 19<smiles>[R]OC(=O)C=C[CH-]CCc1cc(-n2c3ccccc3c3ccccc32)cc(-n2c3ccccc3c3ccccc32)c1</smiles><smiles>CC(C)(Br)C(=O)OCC(COC(=O)C(C)(C)Br)(COC(=O)C(C)(C)Br)COC(=O)C(C)(C)Br</smiles>

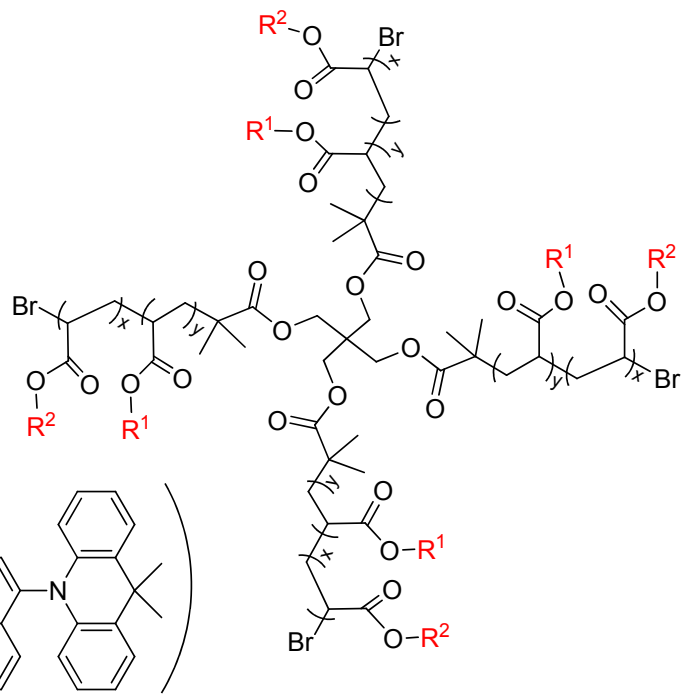


携式测试的薄膜传感器既能高选择性地检测 $\mathrm{F}^{-}$, 也能 够用作痕量水的比色传感器, 用于 $\mathrm{DMSO} / \mathrm{DMF}$ 中水的 高灵敏和快速响应检测 ${ }^{[80]}$.
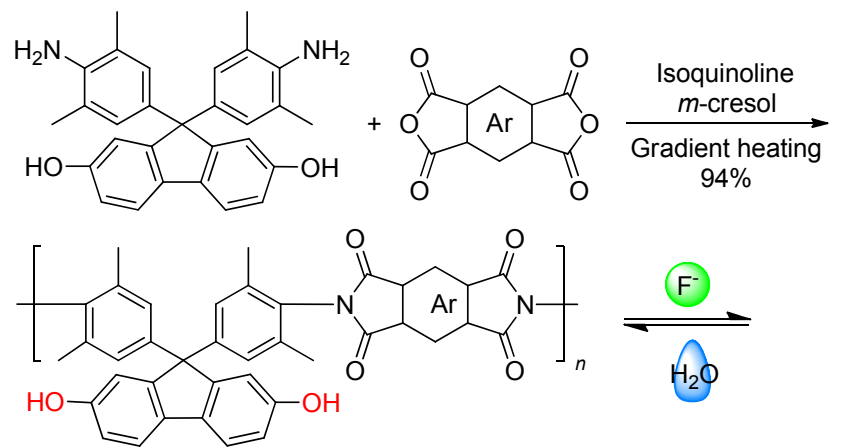

PI

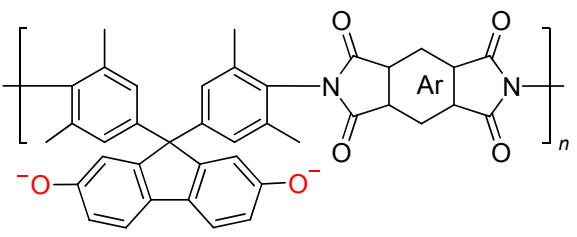

PI-fluoride complex<smiles>CCc1cc(C(C)(C)c2ccc(C)c(C)c2)ccc1C</smiles>

图式 $3 \mathrm{~F}^{-} 、 \mathrm{H}_{2} \mathrm{O}$ 探针的合成及作用机理

Scheme 3 Synthesis and interaction mechanism of a PI probe for $\mathrm{F}^{-}$and $\mathrm{H}_{2} \mathrm{O}$

\section{3 基于缩合反应的聚合物传感器}

醛与胺缩合形成亚胺键, 当多官能团的醛与多官能 才的胺发生缩合时 ${ }^{[81]}$, 可形成基于 $\mathrm{C}=\mathrm{N}$ 键的有机聚合 物 ${ }^{[82]}$. 其中, 较常见的是双醛基化合物与双胺基化合物 间的缩合 ${ }^{[83]}$. 当双醛基化合物中存在邻羟基苯甲醛结 构单元时(Eq. 11) ${ }^{[84]}$, 所形成的 $\mathrm{C}=\mathrm{N}$ 键和邻位的 $\mathrm{OH}$ 可 一起与金属离子 ${ }^{[85]}$ 等作用, 通过影响聚合物的苂光信 号而达到苂光检测的目的.
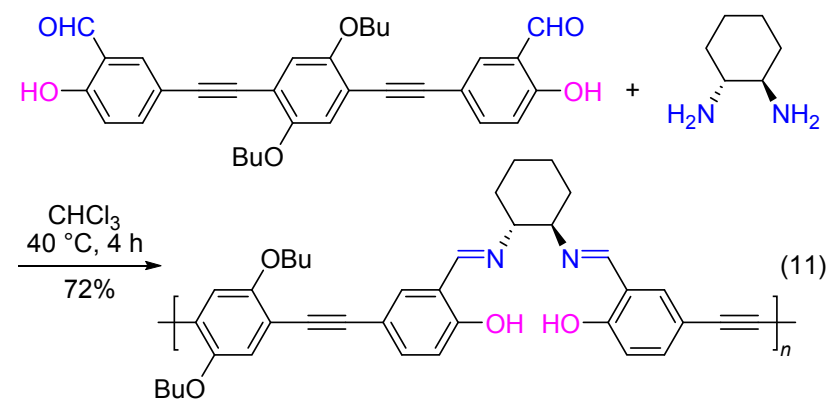

特别是双醛、双胺中还镶嵌有其他发光团(如异喹啉

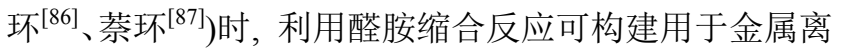

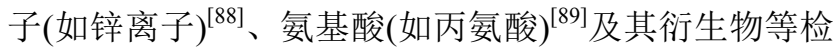
测的有机苂光聚合物探针. 例如, 成义祥课题组 ${ }^{[90]}$ 构建
的手性探针 20 (图 6), $\mathrm{C}=\mathrm{N}$ 键的 $\mathrm{N}$ 原子可与苯丙氨醇的 质子相互作用，通过形成氢键而抑制 PET 过程. 苯丙氨 醇两种对映体与手性聚合物的空间排斥力等手性相互 作用存在差异, 更容易与 $D$-异构体形成稳定络合物, 故 在聚合物的甲苯溶液中加入 $D$-苯丙氨醇，聚合物在 471 $\mathrm{nm}$ 处的苂光强度增强, 肉眼可见苂光颜色变为强亮蓝 色. 但是, 加入 $L$-苯丙氨醇时苂光强度没有变化. 因此, 聚合物对 $D$-苯丙氨醇具有优异的对映选择性能力, 能 实现对苯丙氨醇的手性检测.

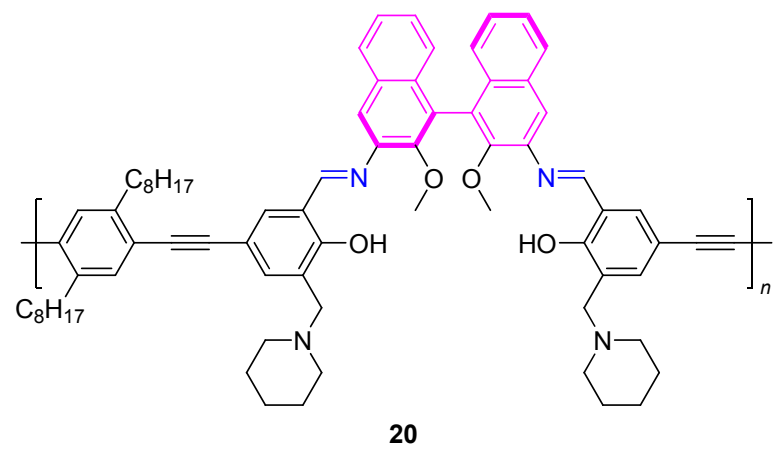

图 6 探针 $\mathbf{2 0}$ 的分子结构

Figure 6 Molecular structure of probe 20

除上述的二胺类化合物外，基于罗丹明苂光团的性 质 ${ }^{[91]}$ ，水合肼与对苯二甲醛的缩合反应(Eq. 12) ${ }^{[92]}$ 也能 用于构建聚合物探针. 例如，汪莉课题组 ${ }^{[92]}$ 将罗丹明-B 均匀地组装到 Eq. 12 所得的聚合物表面, 能得到检测 $\mathrm{O}_{2}{ }^{-}$的聚合物苂光探针. 该探针一般情况下显示的是罗 丹明基团的黄色苂光，但存在 $\mathrm{O}_{2}{ }^{-}$时, $\mathrm{O}_{2}{ }^{--}$的氧化作用会 使罗丹明基团的 $\mathrm{C}-\mathrm{O}-\mathrm{C}$ 键断裂，聚合物与罗丹明基 团之间的强相互作用也被破坏，导致罗丹明基团的苂光 被猝灭，从而使聚合物本身的荧光性质(绿色苂光)被显 示出来, 即探针的荣光颜色由黄色变为绿色. 该探针的 检测限为 $(3.7 \pm 0.42) \mathrm{nmol} \cdot \mathrm{L}^{-1}$, 可用于饮用水和人体血 液中 $\mathrm{O}_{2}{ }^{--}$的检测.

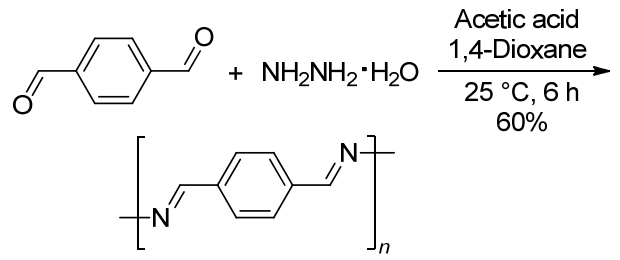

\section{4 基于其他反应的聚合物传感器}

除了上述反应类型外，一些其他类型的反应也可合 成有机聚合物 ${ }^{[93]}$ ，并设计成一些特殊分析物的苂光探 针 $^{[94]}$. 例如, Lippard 课题组 ${ }^{[95]}$ 以含 $\mathrm{N}$ 原子的双鏻盐与双 羰基化合物为原料，通过 Wittig 反应合成有机苂光聚合 物(Eq. 13), 利用其 $\mathrm{N}$ 原子与 $\mathrm{Cu}^{2+}$ 强配位性，设计合成 
了含 $\mathrm{Cu}^{2+}$ 的复合物探针. 向复合物探针中通入 $\mathrm{NO}$ 气 体, 由于 $\mathrm{NO}$ 的强还原性, 复合物探针中的 $\mathrm{Cu}^{2+}$ 被还原 为 $\mathrm{Cu}^{+}$, 导致复合物探针在 $542 \mathrm{~nm}$ 处的苂光强度大大 增强, 苂光颜色为亮绿色, 其对 $\mathrm{NO}$ 的检测限为 6.3 $\mathrm{nmol} \cdot \mathrm{L}^{-1}$. 近来, 还有利用双 Wittig 反应线型聚合得到 有机苂光聚合物, 并设计为金属离子检测探针的报 道 ${ }^{[96]}$.

不仅如此, 经典的 Friedel-Crafts 反应也可构建有机 聚合物苂光探针 ${ }^{[97]}$. 同时, 利用有机磺酸作为催化剂, 三氯三嗪 21 与三苯胺类化合物的新型傅克反应合成了系 列富氮类有机苂光聚合物(如探针 22, 图 7) ${ }^{[98-99]}$. 这类聚 合物可作为电子供体, 在三嗪单元、三苯胺的 $\mathrm{N}$ 原子处 与缺电子的碘发生电子转移形成复合物, 且聚合物具有 较高的 BET 表面积和较大的孔隙体积, 故聚合物对碘 蒸气具有吸附能力, 可用于快速去除或回收碘. 此外, 这些聚合物也可与缺电子的 NAE 进行电子转移, 实现 对 NAE 的检测. 例如, 在探针 22 的四氢呋喃(THF)悬浮 溶液中加入邻硝基苯酚, 聚合物在 $421 \mathrm{~nm}$ 处的荧光会
被完全猝灭，检测限为 $6.32 \times 10^{-10} \mathrm{~mol} \cdot \mathrm{L}^{-1[99]}$. 更换不 同的三苯胺类化合物(图 7)进行反应，可以得到结构、性 能不同的富氮类有机苂光微孔聚合物探针 ${ }^{[98-99]}$.

当然，利用不同的反应可获得对同一检测物种以不 同机理进行检测的有机聚合物荧光探针. 例如，对于 $\mathrm{F}^{-}$ 的检测, 通常是氢键型的 ${ }^{[58,77-79]}$, 即使聚合物探针的类 型与获得方法不同 ${ }^{[100]}$. 但是, $\mathrm{F}^{-}$与缺电子 $\mathrm{B}$ 原子的配位 也可实现对 $\mathrm{F}^{-}$的检测. Chujo 课题组 ${ }^{[101]}$ 以三甲基苯硼烷 和 1,4-二乙炔基苯 1 为原料，利用二个炔基的碀氢化反 应得到有机苂光聚合物(Eq. 14). 基于较强的路易斯酸 碱相互作用, 有机嗍聚合物中 $\mathrm{B}$ 原子的空 $\mathrm{p}$ 轨道会与 $\mathrm{F}^{-}$进行配位, $\mathrm{B}$ 原子的轨道就从 $\mathrm{sp}^{2}$ 变为 $\mathrm{sp}^{3}$, 从而中断 了聚合物 $\pi$-共轭长度的延伸, 导致聚合物的苂光猝灭. 因此, $\mathrm{F}^{-}$存在时, 氯仿溶液中聚合物在 $377 \mathrm{~nm}$ 处的荧光 强度迅速猝灭, 肉眼可见溶液颜色从黄色变为无色. 但 是，其他阴离子 $\left(\mathrm{Cl}^{-} 、 \mathrm{Br}^{-} 、 \mathrm{I}^{-}\right)$对 $\mathrm{F}^{-}$的检测没有影响. 对 $\mathrm{F}^{-}$的检测限，取决于聚合物的分子量.<smiles>[R]c1cc(/C=C/c2cc([R])c(/C=C/c3cc([R])c(/C=C/c4cc([R])c(/C=C/c5cc([R])c(/C=C/c6cc([R])c(CO)cc6[R])cc5[R])cc4[R])cc3[R])cc2[R])c([R])cc1C=O</smiles>

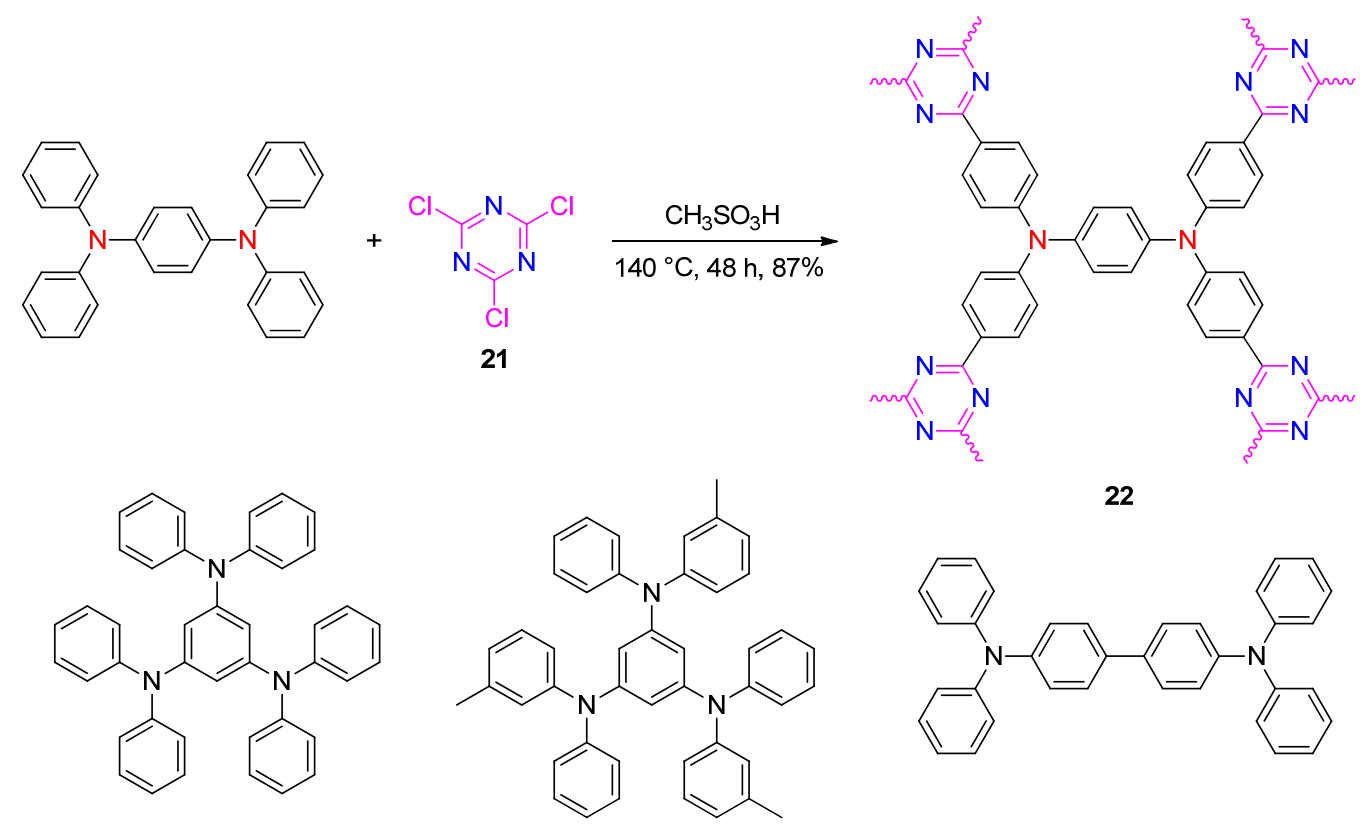

图 7 探针 22 的合成及其他用于该类 Friedel-Crafts 反应芳胺的结构

Figure 7 Synthesis of probe 22 and the structures of other aromatic amines used in this type of Friedel-Crafts reaction 


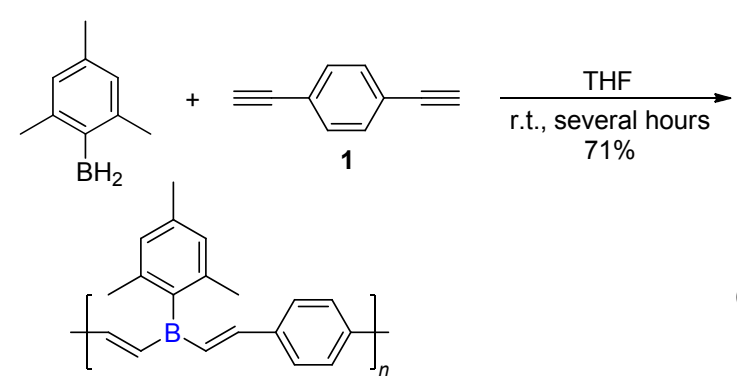

\section{2 基于后期修饰的聚合物荧光传感器}

在先合成有机聚合物的基础上, 再对聚合物的侧链 进行功能化修饰, 这也是一种有机聚合物荧光传感器的 设计方法 ${ }^{[102]}$. 一般而言, 通过对有机聚合物的侧链进 行合理修饰, 特别是利用各种取代反应进行修饰, 可使 得到的有机苂光聚合物传感器的选择性和灵敏度明显 提高 ${ }^{[103]}$. 因此, 侧链的合理设计对构建有机共轭聚合 物荧光材料具有重要意义 ${ }^{[104]}$.

含 $\mathrm{N}$ 基团作为活泼的官能团, 特别是含有 $\mathrm{N}-\mathrm{H}$ 结 构时, 在有机合成与实际应用中非常重要 ${ }^{[05-106]}$. $\mathrm{N}$ 上的 活泼氢容易被取代, 故在对有机胺类聚合物进行修饰 时, 主要是对聚合物中的 $\mathrm{N}$ 原子进行修饰 ${ }^{[107]}$. 其中, 主 要修饰形式是以较大的苂光团取代 $\mathrm{N}$ 原子上的活泼氢, 达到改善传感性能的目的 ${ }^{[108]}$; 或者将 $\mathrm{N}$ 原子离子化以 改善聚合物的水溶性或通透性等 ${ }^{[109]}$.

例如, 沈群东课题组 ${ }^{[110]}$ 利用苯硼酸和聚乙二醇, 对含 $\mathrm{N}-\mathrm{H}$ 结构的聚苆类聚合物中的 $\mathrm{N}$ 原子进行修饰, 构建出具有优异性能的共轭聚合物荧光探针 23 (Scheme 4). 其中, 聚乙二醇链可用来改善原聚合物的 亲水性和细胞通透性; 而引入的苯硼酸基团可作为结合 位点, 使 23 在磷酸盐缓冲盐水 $(\mathrm{pH}=7.4)$ 中与神经递质 多巴胺结合, 形成稳定的苯硼酸酯, 这导致 23 的荧光强 度减弱, 且荧光颜色肉眼可见地从亮绿色变为非常浅的 蓝绿色, 检测极限为 $38.8 \mathrm{nmol} \cdot \mathrm{L}^{-1}$. 由于 23 可用于检测 活的 PC12 细胞和斑马鱼幼虫的大脑中的神经递质多巴 胺, 同时进行荧光成像, 故 23 具有在体内和体外进行多 巴胺传感的巨大潜力.

聚合物的水溶性在生物检测中是不可或缺的, 而离 子型共轭聚合物结合了传统共轭聚合物和聚电解质的 特性, 非常适合地应用于生物传感器 ${ }^{[111]}$. 利用卤代烃 对聚合物侧链中的 $\mathrm{N}$ 原子进行季铵化修饰, 可得到具有 独特的电学和光学特性的共轭离子聚合物 ${ }^{[12-114]}$. 例如, 北京科技大学王国杰课题组 ${ }^{[115]}$ 基于聚(4-乙烯基吡啶) 化合物, 利用溴代萠和碘甲烷进行季铵化反应, 合成了 聚阳离子化合物 24 (Scheme 5), 然后利用静电作用将 24 与多阴离子单链 DNA 结合形成复杂探针. 该探针具 有独特的 AIE 性质. 在探针的水溶液中加入非互补的单

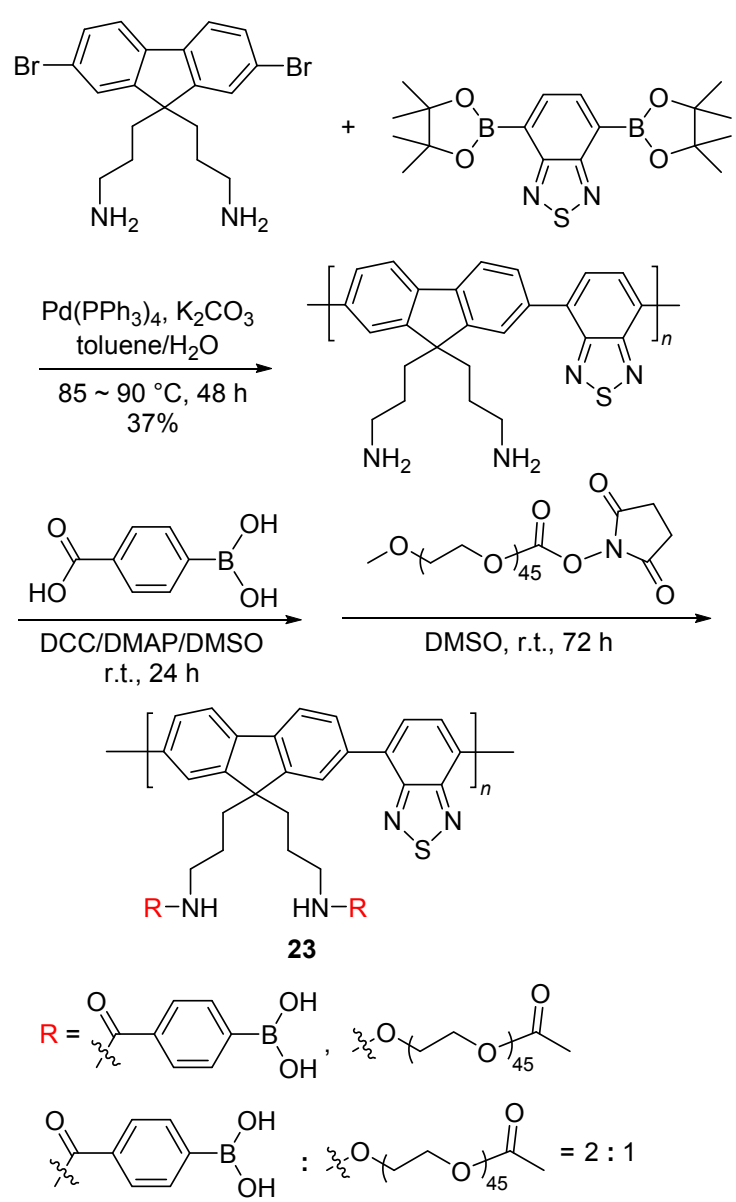

图式 4 探针 23 的合成

Scheme 4 Synthesis of probe $\mathbf{2 3}$

链 DNA 后，由于 AIE 效应，使复合探针的苂光增加; 加 入互补的单链 DNA 后, 由于插入的萠发色团与 DNA 中 的碱基发生电子转移, 导致荧光强度几乎没有变化. 因 此，这种复杂探针可用来检测 DNA 杂化.

在离子型有机苂光聚合物的生物检测方面, 王树 等 ${ }^{[116-117]}$ 对肿瘤细胞的检测与靶向治疗、基因表达的远 程操控 ${ }^{[18]}$ 、诱导细胞的功能调节 ${ }^{[19]}$ 等进行了大量的研 究, 特别是对病原体细胞的识别与清除方面取得了重要 的成果 ${ }^{[120-122]}$. 最近, 他们还利用 Suzuki 偶联反应, 在 钯配合物催化下先制备了带正电荷的聚(芴-亚苯基)衍 生物 25 (Scheme 6), 再将聚合物 25 和带负电荷的 $\mathrm{CdSe} / \mathrm{ZnS}$ 量子点通过静电相互作用, 构建了新型苂光 探针. 其中, 量子点通过荧光能量共振转移使 $\mathbf{2 5}$ 的荧光 发生猝灭. 但是, 当探针与各种病原体相互作用时, 带 负电的微生物与带正电的探针存在竞争性相互作用, 从 而将探针分解，聚合物 $\mathbf{2 5}$ 的荧光恢复. 由于不同的病原 体具有不同的细胞表面电荷和结构, 所恢复的苂光强度 有所不同. 此外, 25 在光照射下具有敏化氧分子或水产 生活性氧的能力, 可有效杀死病原微生物. 因此, 该探 针可以有效地识别和杀死病原微生物 ${ }^{[123]}$. 


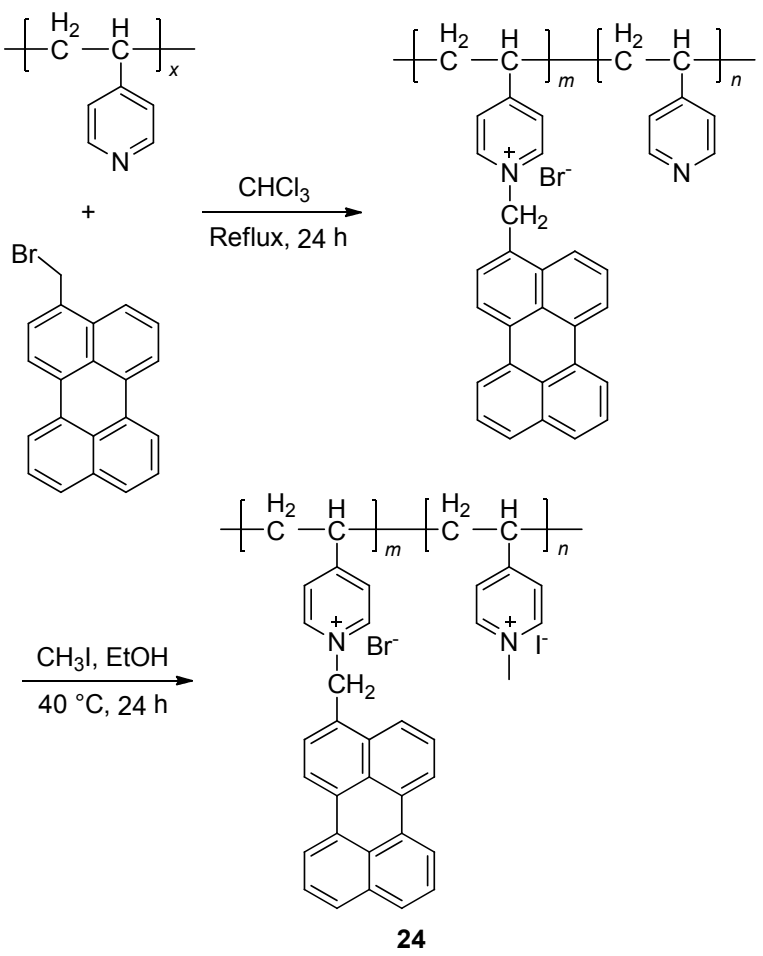

图式 5 探针 24 的合成

Scheme 5 Synthesis of probe $\mathbf{2 4}$

其实, 若是聚合物中存在卤原子 ${ }^{[124]}$, 特别是侧链 存在卤代烃结构时 ${ }^{[125]}$, 或者在聚合后末端存在卤素

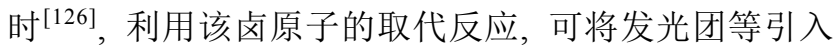
到聚合物中, 构建出不同的荧光探针. 例如, SanzMedel 课题组 ${ }^{[127]}$ 基于溴代聚芴有机苂光聚合物, 利用 聚合物侧链 $\mathrm{Br}$ 原子的取代反应, 将咪唑基团和双键修 饰到聚合物的侧链中, 得到聚合物荧光探针 (Scheme 7). 其中，双键有利于探针通过共价键连接到有机基质中，

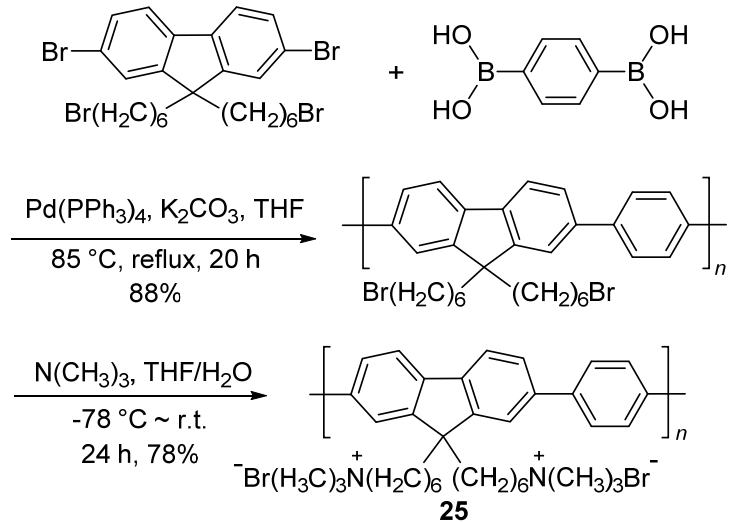

图式 6 聚合物 25 的合成

Scheme 6 Synthesis of polymer 25

形成聚合物微球，从而提高探针的选择性; 而咪唑基团 作为识别元件, 可在水介质中选择性识别 $\mathrm{Cu}^{2+}$, 形成络 合物，从而导致探针的荧光猝灭，其检测限为 $4 \times 10^{-9}$ $\mathrm{mol} \cdot \mathrm{L}^{-1}$. 继续加入 $\mathrm{CN}^{-}$后, 可将络合的 $\mathrm{Cu}^{2+}$ 从探针中 分离出来，使探针的荧光恢复. 因此，该探针可以实现 对 $\mathrm{Cu}^{2+}$ 和 $\mathrm{CN}^{-}$的检测.

\section{3 结束语}

随着有机聚合物苂光传感器不断地发展, 各种各样 的聚合物荧光探针相继被报道. 目前, 这些有机共轭聚 合物苂光探针的制备，通常以金属催化的偶联聚合反应 为主 ${ }^{[128]}$, 应用中以金属离子的检测居多 ${ }^{[129]}$, 但利用各 种聚合反应开发的多功能探针正在兴起 ${ }^{[130]}$. 因此, 基 于更多制备方法的新型多功能有机苂光聚合物的设计 与合成仍有待进一步深入研究，是未来的重点发展方 向.
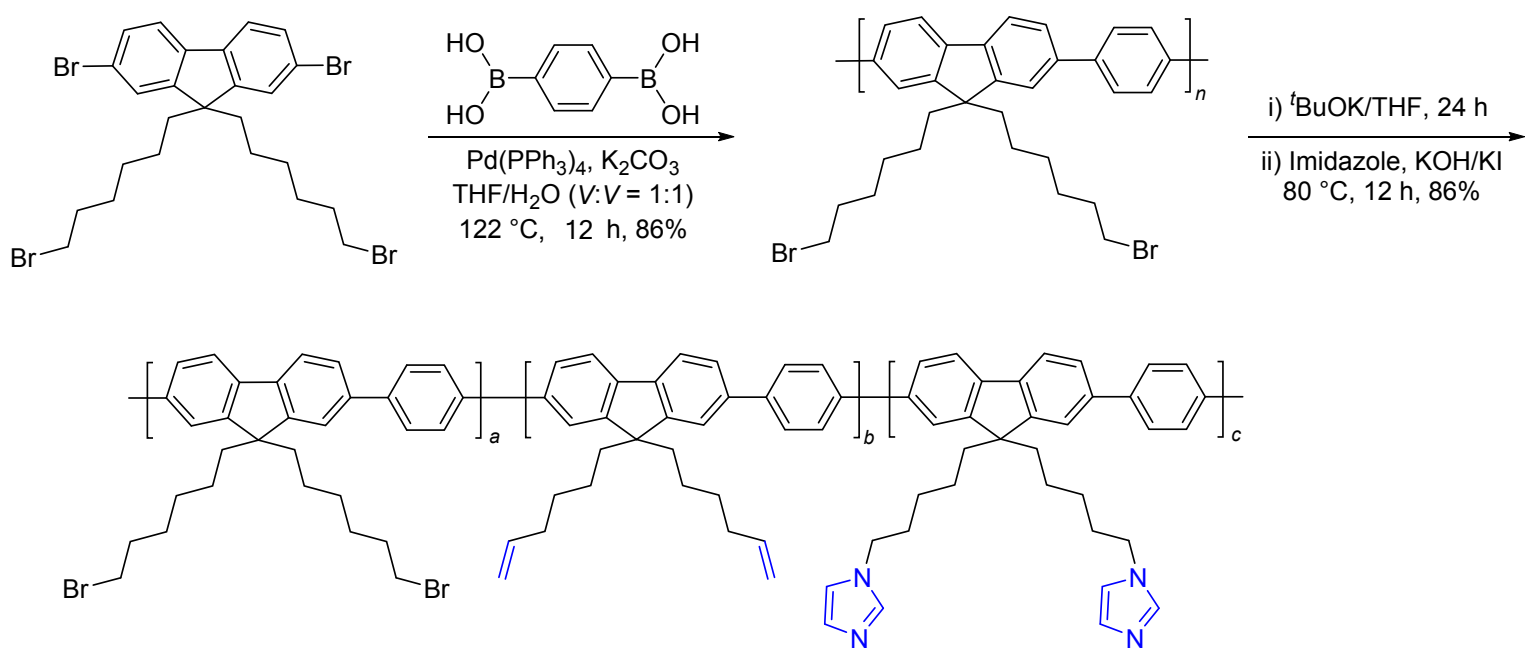

图式 $7 \mathrm{Cu}^{2+}$ 和 $\mathrm{CN}^{-}$探针的合成

Scheme 7 Synthesis of probes for $\mathrm{Cu}^{2+}$ and $\mathrm{CN}^{-}$ 


\section{References}

[1] Kim, S.; Han, T.; Jeong, J.; Lee, H.; Ryou, M. H.; Lee, Y. M. Electrochim. Acta 2017, 241, 553.

[2] Xiong, J.-F.; Luo, S.-H.; Wang, Q.-F.; Wang, Z.-Y. Des. Monomers Polym. 2013, 16, 389.

[3] Wang, Z.-Y.; Hou, X.-N.; Mao, Z.-Z.; Ye, R.-R.; Mo, Y.-Q.; Finlow, D.-E. Iran. Polym. J. 2008, 17, 791.

[4] Graham-Gurysh, E.; Kelkar, S.; McCabe-Lankford, E.; Kuthirummal, N.; Brown, T.; Kock, N. D.; Mohs, A. M.; Levi-Polyachenko, N. ACS Appl. Mater. Interfaces 2018, 10, 7697.

[5] Wu, S. S.; Chen, C. H.; Yang, H. T.; Wei, W.; Wei, M.; Zhang, Y. J.; Liu, S. Q. Sens. Actuators, B 2018, 273, 1047.

[6] Zhang, H.; Dong, X. Z.; Wang, J. H.; Guan, R. F.; Cao, D. X.; Chen, Q. F. ACS Appl. Mater. Interfaces 2019, 11, 32489.

[7] Feng, L. H.; Deng, Y.; Wang, X. J.; Liu, M. G. Sens. Actuators, B 2017, 245, 441.

[8] Reisch, A.; Trofymchuk, K.; Runser, A.; Fleith, G.; Rawiso, M.; Klymchenko, A. S. ACS Appl. Mater. Interfaces 2017, 9, 43030.

[9] Tiwari, M.; Kumar, A.; Shankar, U.; Prakash, R. Biosens. Bioelectron. 2016, 85, 529.

[10] Mettra, B.; Appaix, F.; Olesiak-Banska, J.; Le Bahers, T.; Leung, A.; Matczyszyn, K.; Samoc, M.; van der Sanden, B.; Monnereau, C.; Andraud, C. ACS Appl. Mater. Interfaces 2016, 8, 17047.

[11] Pang, C.-M; Luo, S.-H.; Hao, Z.-F.; Gao, J.; Huang, Z.-H.; Yu, J.-H.; Yu, S.-M.; Wang, Z.-Y. Chin. J. Org. Chem. 2018, 38, 2606 (in Chinese).

(庞楚明, 罗时荷, 郝志峰, 高健, 黄召昊, 余家海, 余思敏, 汪 朝阳，有机化学, 2018, 38, 2606.)

[12] Cai, L.; Xiao, H. M.; Chen, S.; Fu, J. L.; Zhang, Z. H. Microchem. J. 2020, 154, 104603.

[13] Wu, Y. Z.; Dong, Y.; Li, J. F.; Huang, X. B.; Cheng, Y. X.; Zhu, C. J. Chem. Asian J. 2011, 6, 2725.

[14] Long, Y. Y.; Chen, H. B.; Wang, H. M.; Peng, Z.; Yang, Y. F.; Zhang, G. Q.; Li, N.; Liu, F.; Pei, J. Anal. Chim. Acta 2012, 744, 82.

[15] Geng, T. M.; Ye, S. N.; Wang, Y; Zhu, H.; Wang, X.; Liu, X. Talanta 2017, 165, 282.

[16] Balan, B.; Vijayakumar, C.; Tsuji, M.; Saeki, A.; Seki, S. J. Phys. Chem. B 2012, 116, 10371.

[17] Hu, Z.; Yang, T.; Liu, J.; Zhang, Z.; Feng, G. Talanta 2020, 207, 120203.

[18] Li, J. X.; Xue, F. L.; Tan, Y. H.; Luo, S. H.; Wang, Z. Y. Acta Chim. Sinca 2011, 69, 1688 (in Chinese). (李建晓, 薛福玲, 谭越河, 罗时荷, 汪朝阳, 化学学报, 2011, 69, 1688.)

[19] Li, J. X.; Wang, Z. Y.; Xue, F. L.; Luo, S. H. Acta Chim. Sinica 2011, 69, 2835 (in Chinese). (李建晓, 汪朝阳, 薛福玲, 罗时荷, 化学学报, 2011, 69, 2835.)

[20] Liu, J.-L.; Xu, C.-L.; Yang, T.; Hu, Z.-R.; Zhang, Z.-Q.; Feng, G.-D. Spectrochim. Acta, Part A 2019, 222, 117239.

[21] Fan, L.-J.; Zhang, Y.; Jones, W. E. Macromolecules 2005, 38, 2844.

[22] Fan, L.-J.; Jones, W. E. J. Am. Chem. Soc. 2006, 128, 6784

[23] Wu, W.; Chen, A. T.; Tong, L. Y.; Qing, Z. Q.; Langone, K. P.; Bernier, W. E.; Jones, W. E. ACS Sens. 2017, 2, 1337.

[24] Ma, X.; Song, F. Y.; Wang, L.; Cheng, Y. X.; Zhu, C. J. J. Polym. Sci., Part A: Polym. Chem. 2012, 50, 517.

[25] Chen, Z.; Xue, C. H.; Shi, W.; Luo, F. T.; Green, S.; Chen, J.; Liu, H. Y. Anal. Chem. 2004, 76, 6513.

[26] Li, F.; Meng, F. D.; Wang, Y. X.; Zhu, C. J.; Cheng, Y. X. Tetrahedron 2015, 71, 1700.

[27] Zeng, W. F.; Yong, X.; Yang, X. D.; Yan, Y. C.; Lu, X. W.; Qu, J. Q.; Liu, R. Y. Macromol. Chem. Phys. 2014, 215, 1370.
[28] Ji, X. F.; Yao, Y.; Li, J. Y.; Yan, X. Z.; Huang, F. H. J. Am. Chem. Soc. 2013, 135, 74 .

[29] Adachi, N.; Okada, M.; Sugeno, M.; Norioka, T. J. Appl. Polym. Sci. 2016, 133, 1.

[30] Long, Y. Y.; Chen, H. B.; Yang, Y.; Wang, H. M.; Yang, Y. F.; Li, N.; Li, K. A.; Pei, J.; Liu, F. Macromolecules 2009, 42, 6501.

[31] Geng, T.-M.; Zhu, H.; Song, W.; Zhu, F.; Wang, Y. J. Mater. Sci. 2016, 51, 4104.

[32] Geng, T. M.; Li, D. K.; Zhu, Z. M.; Zhang, W. Y.; Ye, S. N.; Zhu, H.; Wang, Z. Q. Anal. Chim. Acta 2018, 1011, 77.

[33] Xiong, J.-F.; Li, J.-X.; Mo, G.-Z.; Huo, J.-P.; Liu, J.-Y.; Chen, X.-Y.; Wang, Z.-Y. J. Org. Chem. 2014, 79, 11619.

[34] Cao, L.; Xiong, J.-F.; Wu, Y.-C.; Ding, S.; Li, M.-B.; Xie, F.; Ma, Z.-H.; Wang, Z.-Y. Chin. J. Org. Chem. 2016, 36, 2053 (in Chinese).

(曹梁，熊金锋，吴彦城，丁沙，李铭冰，谢芬，马志晗，汪朝阳， 有机化学, 2016, 36, 2053.)

[35] Wang, B.-W.; Jiang, K.; Li, J.-X.; Luo, S.-H.; Wang, Z.-Y.; Jiang, H.-F. Angew. Chem., Int. Ed. 2020, 59, 2338.

[36] Jiang, K.; Luo, S.-H.; Pang, C.-M.; Wang, B.-W.; Wu, H.-Q.; Wang, Z.-Y. Dyes Pigm. 2019, 162, 367.

[37] Jiang, K.; Chen, S.-H.; Luo, S.-H.; Pang, C.-M.; Wu, X.-Y.; Wang, Z.-Y. Dyes Pigm. 2019, 167, 164.

[38] Mi, H.-Y.; Liu, J.-L.; Guan, M.-M.; Liu, Q.-W.; Zhang, Z.-Q.; Feng, G.-D. Talanta 2018, 187, 314.

[39] Wang, H. M.; Peng, Z.; Long, Y. Y.; Chen, H. B.; Yang, Y. F.; Li, N.; Liu, F. Talanta 2012, 94, 216.

[40] Huang, Y. Q.; Yao, X.; Zhang, R.; Lang, O. Y.; Jiang, R. C.; Liu, X. F.; Song, C. X.; Zhang, G. W.; Fan, Q. L.; Wang, L. H.; Huang, W. ACS Appl. Mater. Interfaces 2014, 6, 19144.

[41] Zhao, X. Y.; Pinto, M. R.; Hardison, L. M.; Mwaura, J.; Muller, J.; Jiang, H.; Witker, D.; Reynolds, J. R.; Schanze, K. S. V. Macromolecules 2006, 39, 6355

[42] Xie, Y. H.; Zhao, R.; Tan, Y.; Zhang, X.; Liu, F.; Jiang, Y. Y.; Tan, C. Y. ACS Appl. Mater. Interfaces 2012, 4, 405.

[43] Komarova, E.; Bogomolova, A.; Aldissi, M. Polym. Int. 2015, 64, 1451.

[44] Liu, B.; Bazan, G. C. J. Am. Chem. Soc. 2006, 128, 1188.

[45] Kwon, N. Y.; Kim, D.; Son, J. H.; Jang, G. S.; Lee, J. H.; Lee, T. S. Macromol. Rapid Commun. 2011, 32, 1061.

[46] Yang, H.; Duan, C. H.; Wu, Y. S.; Lv, Y.; Liu, H.; Lv, Y. L.; Xiao, D. B.; Huang, F.; Fu, H. B.; Tian, Z. Y. Part. Part. Syst. Charact. 2013, 30, 972 .

[47] Feng, L. H.; Guo, L. X.; Wang, X. J. Biosens. Bioelectron. 2017, $87,514$.

[48] Wang, N.; Arulkumar, M.; Chen, X.-Y.; Wang, B.-W.; Chen, S.-H.; Yao, C.; Wang, Z.-Y. Chin. J. Org. Chem. 2019, 39, 2771 (in Chinese).

(王能, Arulkumar M., 陈孝云, 王柏文, 陈思鸿, 姚辰, 汪朝阳, 有机化学, 2019, 39, 2771.)

[49] Chen, S.-H.; Jiang, K.; Xiao, Y.; Cao, X.-Y.; Arulkumar, M.; Wang, Z.-Y. Dyes Pigm. 2020, 175, 108157

[50] Wu, Y.-C.; You, J.-Y.; Guan, L.-T.; Shi, J.; Cao, L.; Wang, Z.-Y. Chin. J. Org. Chem. 2015, 35, 2465 (in Chinese).

(吴彦城, 尤嘉宜, 关丽涛, 石杰, 曹梁, 汪朝阳, 有机化学, 2015, 35, 2465.)

[51] Jiang, K.; Cao, L.; Hao, Z.-F.; Chen, M.-Y.; Cheng, J.-L.; Li, X.; Xiao, P.; Chen, L.; Wang, Z.-Y. Chin. J. Org. Chem. 2017, 37, 2221 (in Chinese)

(蒋凯, 曹梁, 郝志峰, 陈美燕, 程洁鸾, 李晓, 肖萍, 陈亮, 汪 朝阳, 有机化学, 2017, 37, 2221.)

[52] Giri, D.; Bankura. A.; Patra, S. K. Polymer 2018, 158, 338. 
[53] Diao, H. P.; Guo, L. X.; Liu, W.; Feng, L. H. Spectrochim. Acta, Part A 2018, 196, 274

[54] Jo, S.; Kim, J.; Noh, J.; Kim, D.; Jang, G.; Lee, N.; Lee, E.; Lee, T. S. ACS Appl. Mater. Interfaces 2014, 6, 22884.

[55] Yu, Y. G.; Xu, W.; Fu, Y. Y.; Cao, H. M.; He, Q. G..; Cheng, J. G. Dyes Pigm. 2020, 172, 107852.

[56] Wu, Y.-C.; You. J.-Y.; Jiang, K.; Xie, J.-C.; Li, S.-L.; Cao, D.; Wang, Z.-Y. Dyes Pigm. 2017, 140, 47.

[57] Zhang, H. M.; Wu, Y. C.; You, J. Y.; Cao, L.; Ding, S.; Jiang, K.; Wang, Z. Y. Chin. J. Org. Chem. 2016, 36, 2559 (in Chinese). (张惠敏, 吴彦城, 尤嘉宜, 曹梁, 丁沙, 蒋凯, 汪朝阳, 有机化 学, 2016, 36, 2559.)

[58] Zhang, H. C.; Yang, K.; Chen, C.; Wang, Y. H.; Zhang, Z. Z.; Tang, L. L.; Sun, Q. K.; Xue, S. F.; Yang, W. J. Polymer 2018, 149, 266.

[59] Wang, C.-H.; Nesterov, E. E. Chem. Commun. 2019, 55, 8955.

[60] Tang, Y. L.; Liu, Y.; Cao, A. Anal. Chem. 2013, 85, 825.

[61] Seo, S.; Kim, J.; Jang, G.; Kim, D.; Lee, T. S. ACS Appl. Mater. Interfaces 2014, 6, 918.

[62] Wei, G.; Meng, F. D.; Wang, Y. X.; Cheng, Y. X.; Zhu, C. J. Macromol. Rapid Commun. 2014, 35, 2077.

[63] Zhang, J. Y.; Zhao, L. K.; Dong, L. J.; Nie, X. Y.; Cheng, Y. Q. Talanta 2018, 190, 475.

[64] Zhang, Z.; Fang, X. F.; Liu, Z. H.; Liu, H. C.; Chen, D. D.; He, S. Q.; Zheng, J.; Yang, B.; Qin, W. P.; Zhang, X. J.; Wu, C. F. Angew. Chem., Int. Ed. 2020, 59, 3691.

[65] Yang, Y. Q.; Fan, X. X.; Li, L.; Yang, Y. M.; Nuernisha, A.; Xue, D. W.; He, C.; Qian, J.; Hu, Q. L.; Chen, H.; Liu, J.; Huang, W. ACS Nano 2020, 14, 2509.

[66] Gong, D. Y.; Cao, T.; Han, S. C.; Zhu, X. T.; Iqbal, A.; Liu, W. S.; Qin, W. W.; Guo, H. C. Sens. Actuators, B 2017, 252, 577.

[67] Geng, T.-M.; Zhang, W.-Y.; Li, D.-K.; Xia, H.-Y.; Wang, Y.; Wang, Z.-Q.; Zhu, Z.-M.; Zheng, Q. J. Environ. Chem. Eng. 2017, 5, 906.

[68] Geng, T.-M.; Wang, X.; Zhu, F.; Jiang, H.; Wang, Y. Bull. Mater. Sci. 2017, 40, 187.

[69] Vallejos, S.; Munoz, A.; Ibeas, S.; Serna, F.; Garcia, F. C.; Garcia, J. M. ACS Appl. Mater. Interfaces 2015, 7, 921

[70] Chen, S.-H.; Pang, C.-M.; Chen, X.-Y.; Yan, Z.-H.; Huang, S.-M.; Li, X.-D.; Zhong, Y.-T.; Wang, Z.-Y. Chin. J. Org. Chem. 2019, 39, 1846 (in Chinese).

(陈思鸿, 庞楚明, 陈孝云, 严智浩, 黄诗敏, 李香弟, 钟雅婷, 汪朝阳，有机化学, 2019, 39, 1846.)

[71] Pang, C.-M.; Luo, S.-H.; Jiang, K.; Wang, B.-W.; Chen, S.-H.; Wang, N.; Wang, Z.-Y. Dyes Pigm. 2019, 170, 107651.

[72] Buruiana, E. C.; Stroea, L.; Buruiana, T. Polym. J. 2009, 41, 694.

[73] Geng, T.-M.; Guo, C.; Dong, Y.-J.; Chen, M.; Wang, Y. Polym. Adv. Technol. 2016, 27, 90.

[74] Terra, I. A. A.; Sanfelice, R. C.; Scagion, V. P.; Tomazio, N. B.; Mendonca, C. R.; Nunes, L. A. O.; Correa, D. S. J. Appl. Polym. Sci. 2019, 136, 47775 .

[75] Zhang, L. Q.; Su, F. Y.; Buizer, S.; Kong, X. X.; Lee, F.; Day, K.; Tian, Y. Q.; Meldrum, D. R. Chem. Commun. 2014, 50, 6920.

[76] Christopherson, C. J.; Mayder, D. M.; Poisson, J.; Paisley, N. R.; Tonge, C. M.; Hudson, Z. M. ACS Appl. Mater. Interfaces 2020, 12, 20000.

[77] Wu, Y. C.; Liu, S. M.; Chen, Z. G.; Zhao, J. Q. Dyes Pigm. 2020, 173, 107924.

[78] Wu, Y. C.; Shi, C. Q.; Chen, Z. G.; Zhou, Y. B.; Liu, S. M.; Zhao, J. Q. Polym. Chem. 2019, 10, 1399.

[79] Zhou, Z. X.; Huang, W. X.; Long, Y. B.; Chen, Y. Q.; Yu, Q. X.; Zhang, Y.; Liu, S. W.; Chi, Z. G.; Chen, X. D.; Xu, J. R. J. Mater. Chem. C 2017, 5, 8545 .

[80] Wu, Y. C.; Ji, J. Q.; Zhou, Y. B.; Chen, Z. G.; Liu, S. M.; Zhao, J. Q.
Anal. Chim. Acta 2020, 1108, 35

[81] Gong, F. C.; Zou, W.; Wang, Q. G.; Deng, R. X.; Cao, Z.; Gu, T. T. Microchem. J. 2019, 148, 767.

[82] Wang, L.; Song, F. Y.; Hou, J. L.; Li, J. F.; Cheng, Y. X.; Zhu, C. J. Polymer 2012, 53, 6033.

[83] Song, F. Y.; Wei, G.; Wang, L.; Jiao, J. M.; Cheng, Y. X.; Zhu, C. J. J. Org. Chem. 2012, 77, 4759.

[84] Xu, Y.; Meng, J.; Meng, L. X.; Dong, Y.; Cheng, Y. X.; Zhu, C. J. Chem.-Eur. J. 2010, 16, 12898.

[85] Meng, F. D.; Li, F.; Yang, L.; Wang, Y. X.; Quan, Y. W.; Cheng, Y. X. Polym. Chem. 2018, 56, 1282.

[86] Song, F. Y.; Ma, X.; Hou, J. L.; Huang, X. B.; Cheng, Y. X.; Zhu, C. J. Polymer 2011, 52, 6029.

[87] Wang, L.; Li, F.; Liu, X. H.; Wei, G.; Cheng, Y. X.; Zhu, C. J. J. Polym. Sci., Part A: Polym. Chem. 2013, 51, 4070.

[88] Dong, Y.; Wu, Y. Z.; Jiang, X. X.; Huang, X. B.; Cheng, Y. X.; Zhu, C. J. Polymer 2011, 52, 5811.

[89] Hou, J. L.; Song, F. Y.; Wang, L.; Wei, G.; Cheng, Y. X.; Zhu, C. J. Macromolecules 2012, 45, 7835.

[90] Wei, G.; Zhang, S. W.; Dai, C. H.; Quan, Y. W.; Cheng, Y. X.; Zhu, C. J. Chem.-Eur. J. 2013, 19, 16066.

[91] Childress, E. S.; Roberts, C. A.; Sherwood, D. Y.; LeGuyader, C. L. M.; Harbron, E. J. Anal. Chem. 2012, 84, 1235.

[92] Du, Y.; Song, Y. H.; Hao, J.; Cai, K. Y.; Liu, N.; Yang, L.; Wang, L. Talanta 2019, 198, 316.

[93] Geng, T. M.; Zhu, Z. M.; Wang, X.; Xia, H. Y.; Wang, Y.; Li, D. K. Sens. Actuators, B 2017, 244, 334.

[94] Hegarty, C.; Kirkwood, S.; Cardosi, M. F.; Lawrence, C. L.; Taylor, C. M.; Smith, R. B.; Davis, J. Microchem. J. 2018, 139, 210.

[95] Smith, R. C.; Tennyson, A. G.; Lim, M. H.; Lippard, S. J. Org. Lett. 2005, 7, 3573.

[96] Gao, Z.-Y.; Zhang, X.; Xing, S.; Lu, Q.; Yao, J.-S.; Liu, Q.-Z.; Qiao, C.-D.; Xie, R.-X.; Ding, B.-Y. Dyes Pigm. 2019, 168, 68.

[97] Fei, T.; Jiang, K.; Liu, S.; Zhang, T. RSC Adv. 2014, 4, 21429.

[98] Geng, T. M.; Zhu, Z. M.; Zhang, W. Y.; Wang, Y. J. Mater. Chem. A 2017, 5, 7612 .

[99] Geng, T. M.; Ye, S. N.; Zhu, Z. M.; Zhang, W. Y. J. Mater. Chem. A 2018, 6, 2808.

[100] Tang, Q.; Nie, H.-M.; Gong, C.-B.; Liu, H.-D.; Xiao, K. RSC $A d v$. 2015, 5, 3888

[101] Miyata, M.; Chujo, Y. Polym. J. 2002, 34, 967.

[102] Shan, Y. R.; Yao, W. J.; Liang, Z. Q.; Zhu, L. H.; Yang, S. B.; Ruan, Z. J. Dyes Pigm. 2018, 156, 1.

[103] Kumar, V.; Maiti, B.; Chini, M. K.; De, P.; Satapathi, S. Sci. Rep. 2019, 9, 7269.

[104] Bao, Y. Y.; Wang, T. S.; Li, Q. B.; Du, F. F.; Bai, R. K.; Smet, M.; Dehaen, W. Polym. Chem. 2013, 5, 792.

[105] Liu, Z. S.; Zeng, H.; Zhang, W. J.; Song, C.; Yang, F.; Liu, Y.; Zhu, J. Polymer 2019, 172, 152.

[106] Yao, C. Z.; Li, Y. M.; Wang, Z. X.; Song, C. Z.; Hu, X. L.; Liu, S. Y. ACS Nano 2020, 14, 1919.

[107] Chen, J.; Tang, Y.; Wang, H.; Zhang, P. S.; Li, Y.; Jiang, J. H. J. Colloid Interface Sci. 2016, 484, 298.

[108] Hiruta, Y.; Funatsu, T.; Matsuura, M.; Wang, J.; Ayano, E.; Kanazawa, H. Sens. Actuators, B 2015, 207, 724.

[109] Su, F. Y.; Agarwal, S.; Pan, T. T.; Qiao, Y.; Zhang, L. Q.; Shi, Z. W.; Kong, X. X.; Day, K.; Chen, M. W.; Meldrum, D.; Kodibagkar, V. D.; Tian, Y. Q. ACS Appl. Mater. Interfaces 2018, 10, 1556.

[110] Qian, C.-G.; Zhu, S.; Feng, P.-J.; Chen, Y.-L.; Yu, J.-C.; Tang, X.; Liu, Y.; Shen, Q.-D. ACS Appl. Mater. Interfaces 2015, 7, 18581.

[111] Peng, H.; Soeller, C.; Travas-Sejdic, J. Chem. Commun. 2006, 35, 3735. 
[112] Sun, B.; Sun, M.-J.; Gu, Z.; Shen, Q.-D.; Jiang, S.-J.; Xu, Y.; Wang, Y. Macromolecules 2010, 43, 10348.

[113] Ma, H. C.; Qin, Y. F.; Yang, Z. M.; Yang, M. Y.; Ma, Y. C.; Yin, P.; Yang, Y.; Wang, T.; Lei, Z. Q.; Yao, X. Q. ACS Appl. Mater. Interfaces 2018, 10, 20064.

[114] Sabater, P.; Zapata, F.; Bastida, A.; Caballero, A. Org. Biomol. Chem. 2018, 18, 3858.

[115] Wang, G. J.; Zhang, R. C.; Xu, C.; Zhou, R. Y.; Dong, J.; Bai, H. T.; Zhan, X. W. ACS Appl. Mater. Interfaces 2014, 3, 11136.

[116] Fu, X. C.; Bai, H. T.; Lyu, F. T.; Liu, L. B.; Wang, S. Chem. Res. Chin. Univ. 2020, 36, 237.

[117] Khatoon, S. S.; Chen, Y. Y.; Zhao, T.; Liu, L. B.; Wang, S. Biomater. Sci. 2020, 8, 2156.

[118] Wang, Y. X.; Li, S L.; Zhang, P. B.; Bai, H. T.; Feng, L. H.; Lv, F. T.; Liu, L. B.; Wang, S. Adv. Mater. 2018, 30.

[119] Liu, Y. Q.; Tian, L. Y.; Li, Y.; Chen, Y. Y.; Chen, Y. D.; Liu, L. B.; Wang, S. ACS Appl. Mater. Interfaces 2019, 12, 3438.

[120] Liu, L.; Wang, X. Y.; Zhu, S. X.; Yao, C.; Ban, D. D.; Liu, R. H.; Li, L. D.; Wang, S. Chem. Mater. 2020, 32, 438.
[121] Zhang, P. B.; Xu, C. L.; Zhou, X.; Qi, R. L.; Liu, L. B.; Lv, F. T.; Li, Z. P.; Wang, S. Colloids Surf., B 2020, 188.

[122] Zhu, C. L.; Yang, Q.; Liu, L. B.; Wang, S. Angew. Chem., Int. Ed. 2011, 50, 9607.

[123] Yuan, H. T.; Zhao, H.; Peng, K.; Qi, R. L.; Bai, H. T.; Zhang, P. B.; Huang, Y. M.; Lv, F. T.; Liu, L. B.; Bao, J. C.; Wang, S. ACS Appl. Mater. Interfaces 2020, 12, 21263.

[124] Fernandez-Alonso, S.; Corrales, T.; Pablos, J. L.; Catalina, F. Sens. Actuators, B 2018, 270, 256.

[125] Jiang, Y. Y.; Cui, D.; Fang, Y.; Zhen, X.; Upputuri, P. K.; Pramanik, M.; Ding, D.; Pu, K. Y. Biomaterials 2017, 145, 168.

[126] Hong, S. W.; Ahn, C. H.; Huh, J.; Jo, W. H. S. Macromolecules 2006, 39, 7694.

[127] Alvarez-Diaz, A.; Salinas-Castillo, A.; Camprubi-Robles, M.; Costa-Fernandez, J. M.; Pereiro, R.; Mallavia, R.; Sanz-Medel, A. Anal. Chem. 2011, 83, 2712.

[128] Rochat, S.; Swager, T.-M. Angew. Chem., Int. Ed. 2014, 53, 9792.

[129] Tavoli, F.; Alizadeh, N. Anal. Chim. Acta 2016, 946, 88.

[130] Das, K. R.; Antony, M. J.; Varghese, S. Polymer 2019, 181, 121747.

(Fan, Y.) 